\title{
Experimental investigation on the effects of process parameters of GMAW and transient thermal analysis of AISI321 steel
}

\author{
A. G. Kamble $\cdot$ R. Venkata Rao
}

Received: 31 May 2013/Accepted: 23 September 2013/Published online: 24 October 2013

(C) Shanghai University and Springer-Verlag Berlin Heidelberg 2013

\begin{abstract}
Gas metal arc welding (GMAW) develops an arc by controlling the metal from the wire rod and the input process parameters. The deposited metal forms a weld bead and the mechanical properties depend upon the quality of the weld bead. Proper control of the process parameters which affect the bead geometry, the microstructures of the weldments and the mechanical properties like hardness, is necessary. This experimental study aims at developing mathematical models for bead height $\left(H_{\mathrm{B}}\right)$, bead width $\left(W_{\mathrm{B}}\right)$ and bead penetration $\left(P_{\mathrm{B}}\right)$ and investigating the effects of four process parameters viz: welding voltage, welding speed, wire feed rate and gas flow rate on bead geometry, hardness and microstructure of AISI321 steel with $10 \mathrm{~mm}$ thickness. The transient thermal analysis shows temperature and residual stress distributions at different conduction and convection conditions.
\end{abstract}

Keywords Gas metal arc welding (GMAW) .

Mathematical modeling $\cdot$ Microstructure $\cdot$ Transient thermal analysis

\section{Introduction}

After fusion welding, two separate parts are joined by the melting and subsequent solidification of adjacent areas. Heat flow during welding not only controls the size of the fusion, but also affects the properties of the weldment. The temperature distribution within weldment plays an important

A. G. Kamble $(\bowtie) \cdot$ R. V. Rao

Department of Mechanical Engineering, Sardar Vallabhbhai

National Institute of Technology, Ichchanath, Surat 395007,

Gujarat, India

e-mail: avi_nash1000@yahoo.co.in role on changing the mechanical and thermal properties of the weldment. These properties also depend on the chemical composition and the bead geometry. Gas metal arc welding (GMAW) has the advantages of high efficiency, good weld quality, and low production cost. At the same time, it is also easy to realize automation in manufacturing and widely be used in the industry. Therefore, this process is generally accepted today as the preferred joining technique and commonly chosen for assembling large metal structures such as bridges, automobiles, aircrafts, ships and rolling stocks. All major commercial metals welded by GMAW process include carbon steel, low and high alloy steels, stainless steel, aluminum, copper, titanium, and nickel alloy $[1,2]$. If the arc is properly controlled in GMAW process, the metal from the electrode will pass through the arc and deposit on the base metal. When the filler wire moves at a correct speed, the metal can be deposited in a uniform layer on the base metal called bead [3]. In order to utilize these principles, some means of controlling the power (voltage and current) is essential. However, the voltage is governed by the arc length which in turn depends on the electrode diameter. The selection of current and voltage is according to the size of the work piece and the position to be welded.

The quality of weld is determined by weld bead geometry parameters which depend on the input process parameters. Therefore, choosing an appropriate set of welding parameters becomes one of the most important tasks in welding process. Tham et al. [4] investigated the correlation between welding parameters (arc voltage, welding current and welding speed) and bead geometry of $3 \mathrm{~F}$ fillet joint welded in downhill position by GMAW. The consumable was ER70S$61.2 \mathrm{~mm}$ solid wire and shielded by carbon dioxide. Articulated welding robot performed a welding of $6 \mathrm{~mm}$ carbon steel T-joint. Mathematical models and calculator were developed to display the values of weld bead geometry for 
any value of welding parameter and vice versa. The deviation between predicted weld bead geometry and actual experimental record was less than $1.0 \mathrm{~mm}$. Based on the actual weld pool geometry and the dimensions calculated from a numerical model, a hydrostatic model for liquid metal surface was used by $\mathrm{Xu}$ et al. [5] to study the onset of bed undercut defects in the high speed GMAW process and the effects of different welding parameters on the bed undercut tendency. Simulation and optimization of weld bead geometry parameter using artificial neural network (ANN) and particle swarm optimization (PSO) algorithm were carried out by Katherasan et al. [6]. The input process variables considered were wire feed rate, voltage, welding speed, torch angle, and the output process parameters were weld bead width, reinforcement and depth of penetration. The material used for experiment was $316 \mathrm{~L}(\mathrm{~N})$ of $8 \mathrm{~mm}$ thickness, and the filler wire was in same grade of $1.2 \mathrm{~mm}$ diameter. The results were fed to the ANN algorithm for establishing a relationship between the input and the output parameters. The results were then embedded into the PSO algorithm which optimized the process parameters. Rao et al. [7] used Taguchi experimental design to develop the mathematical models that correlated welding process parameters to weld bead geometry with experimental investigation using regression analysis. Five process parameters such as wire feed rate, plate thickness, pulse frequency, wire feed rate to travel speed, peak current were selected with the width, reinforcement and penetration as output parameters. The mild steel plates of different thickness were used for experimentation. Campbell et al. [8] developed an ANN model for the prediction of weld geometry produced using GMAW process with alternating shielding gases. This method supplied two individual shielding gases to develop the weld area in which the gases were discretely supplied at a given frequency. The models were used to predict the penetration, leg length, and effective throat thickness under a given set of weld parameters and alternate frequency of shielding gas. The material used was $6 \mathrm{~mm}$ thickness DH36 grade steel in the form of $60 \mathrm{~mm}$ wide bar. Ganjigatti et al. [9] employed full factorial design to correlate the metal inert gas (MIG) process parameters like welding speed, welding voltage, wire feed rate, gas flow rate, nozzle-to-plate distance, torch angle as the input parameters, and the responses considered were bead height $\left(H_{\mathrm{B}}\right)$, bead width $\left(W_{\mathrm{B}}\right)$ and bead penetration $\left(P_{\mathrm{B}}\right)$. The structural mild steel plates were used as the base material. Three linear regression analysis approaches and one non-linear regression analysis approach were developed and their performances were compared.

Shiang et al. [10] coupled principal component analysis (PCA) with Taguchi methods to optimize multiple quality characteristics like hardness and the bending strength of the weldment of aluminum foam plates of $10 \mathrm{~mm}$ thickness. Eight selected control factors were: type of filler material, current, welding speed, gas flow rate, work piece gap, arc angle, groove angle, and electrode extension length. The experimental results showed that the optimal process design could indeed improve the multiple quality characteristics. Pal et al. [11] monitored the weld joint strength in pulsed MIG welding process for mild steel plate of $8 \mathrm{~mm}$ thickness. A multilayer neural network model was developed to predict the ultimate tensile stress of welded plates. There were six process parameters, namely pulse voltage, back-ground voltage, pulse duration, pulse frequency, wire feed rate and the welding speed. The ultimate tensile strength of the welded plate was considered as the output variable. Furthermore, output obtained through multiple regression analysis (MRA) was used to compare with an ANN model output. It was found that the welding strength predicted by the ANN model was better than that based on PSO used by MRA. Malviya and Pratihar [12] carried out both forward and reverse mappings of MIG welding process by tuning in the neural networks. The chosen input parameters were welding speed, welding voltage, wire feed rate, gas flow rate, nozzle-to-plate distance, torch angle, and the responses were $H_{\mathrm{B}}, W_{\mathrm{B}}$ and $P_{\mathrm{B}}$. A mild steel plate of $8 \mathrm{~mm}$ thickness was used. Four approaches were developed and their performances were compared. In addition, literatures review on the application of experiment design, evolutionary algorithm and computational networks had been made by Benyounis and Olabi [13] to develop mathematical models between input and output parameters of different welding processes and to determine the welding input parameters that lead to the desired weld quality.

It is observed from the literatures that previously researchers used different input process parameters like open circuit voltage, welding current, wire feed rate, welding speed, nozzle-to-plate distance, work piece thickness, pulse frequency, gas flow rate, torch angle, etc., and output process parameters like $H_{\mathrm{B}}, W_{\mathrm{B}}$ and $P_{\mathrm{B}}$, percentage dilution and hardness, etc., for GMAW process on work piece materials of different thickness. Mathematical models were developed and optimization techniques were used to predict the process parameters. AISI321 steel has many applications such as diesel and heavy duty automotive exhaust systems, firewalls, stack liners, boiler casings, welded pressure vessels, jet aircraft components, radiant superheaters, bellows and oil refinery equipment, etc. The investigation on effects of welding process parameters on AISI321 steel is thus very essential. In order to obtain good weld bead, proper input welding process parameters should be selected to optimize the economics of the welding operations in terms of productivity, total cost and other criteria. This research work develops the mathematical models for bead geometry parameters and investigates the effects of input process parameters of GMAW process on bead geometry, mechanical properties such as hardness and microstructures in various zones of the weldment. In 
addition, transient thermal analyses of AISI321 steel weldments using ANSYS simulation software are carried out.

\section{Methodology}

\subsection{GMAW machine}

The experiments are carried out on a 3-phase, $50 \mathrm{~Hz}$ frequency, $300 \mathrm{~A}$, forced air cooling semiautomatic machine manufactured by ATE, Pune, India. The torch is fixed to the frame at $90^{\circ}$ to the work piece. The work piece on trolley moves in perfect path and the gas flow rate, wire feed rate, welding voltage are adjusted on the machine. The variation in the voltage automatically changes the current. Hence, current is not considered as an input parameter in the experiments. Therefore, four input process parameters, viz: welding voltage, wire feed rate, gas flow rate and welding speed have influence on the weld bead geometry, hardness and microstructure. Figure 1 shows the GMAW machine setup.

\subsection{AISI321 grade steel and sample preparation}

The AISI321 is a stabilized austenite stainless steel which is similar to AISI304, however the content of titanium is five times the carbon, which reduces or prevents carbide precipitation during welding. It has excellent resistance to oxidation and corrosion, at the same time possesses good

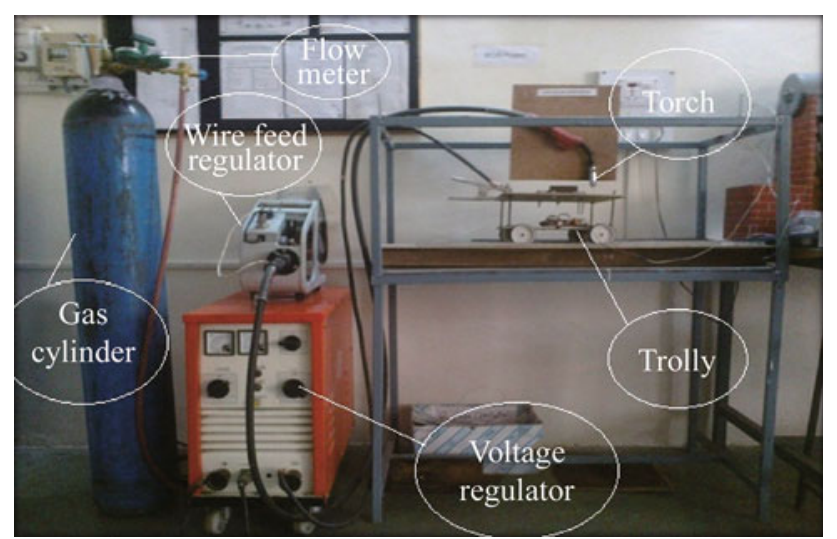

Fig. 1 GMAW machine setup creep strength. It is used primarily in the applications involving continuous and intermittent service temperatures with the carbide precipitation ranging in $700-1,089 \mathrm{~K}$. It is welded by common fusion and resistance techniques. The filler wire rod of AISI308 grade is recommended for welding AISI321 grade steel. The chemical compositions of both AISI321 and AISI308 are given in Table 1.

The AISI321 steel plate pieces of $150 \mathrm{~mm} \times 120 \mathrm{~mm} \times$ $10 \mathrm{~mm}$ size are prepared. The $\mathrm{V}$-groove of $30^{\circ}$ is given to each work piece as per design on the $120 \mathrm{~mm}$ side of plate. Figure 2 shows a pair of specimens ready to weld.

\subsection{Selection of process parameter and design matrix}

Process parameters play a very important role in determining good weld bead geometry [14]. Therefore, proper selection of welding parameters is required. Different welding parameters to be selected are welding voltage, welding speed, wire feed rate, gas flow rate, and the output responses are $H_{\mathrm{B}}, W_{\mathrm{B}}$ and $P_{\mathrm{B}}$. Moreover, the weld bead geometry will influence the mechanical properties of the weldment. Therefore, mechanical properties such as hardness are also considered as an output parameter. The input and output process parameters are given in Fig. 3.

The four process parameters are at five levels. These controllable process parameters are identified based on their effects on weld bead geometry and good appearance of the weld bead. It is desirable to have five minimum levels of process parameters to reflect the true behavior of response parameters. The working range of each process parameter is chosen by taking various trials for a smooth

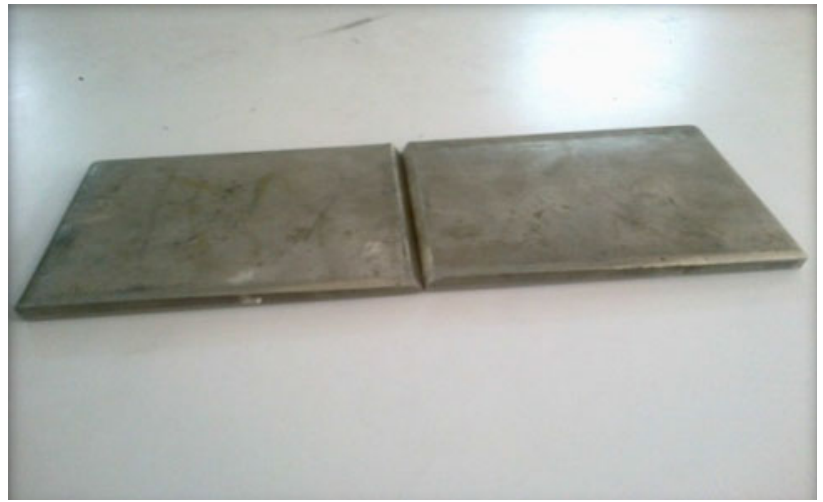

Fig. 2 Pair of specimens

Table 1 Chemical composition of material

\begin{tabular}{|c|c|c|c|c|c|c|c|c|c|c|c|c|c|c|}
\hline & \multicolumn{14}{|c|}{ Composition/\% } \\
\hline & $\mathrm{C}$ & $\mathrm{Si}$ & $\mathrm{Mn}$ & S & $\mathrm{P}$ & $\mathrm{Cr}$ & $\mathrm{Ni}$ & Mo & Co & $\mathrm{Ti}$ & V & $\mathrm{Cu}$ & $\mathrm{Nu}$ & $\mathrm{Fe}$ \\
\hline AISI321 & 0.042 & 0.334 & 1.168 & 0.019 & 0.028 & 17.190 & 9.065 & 0.357 & 0.280 & 0.293 & 0.065 & 0.044 & 0.025 & 71.090 \\
\hline AISI308 & 0.025 & 0.870 & 0.760 & 0.010 & 0.017 & 19.400 & 9.802 & 0.246 & 0.218 & 0.312 & 0.042 & 0.036 & 0.063 & 68.172 \\
\hline
\end{tabular}




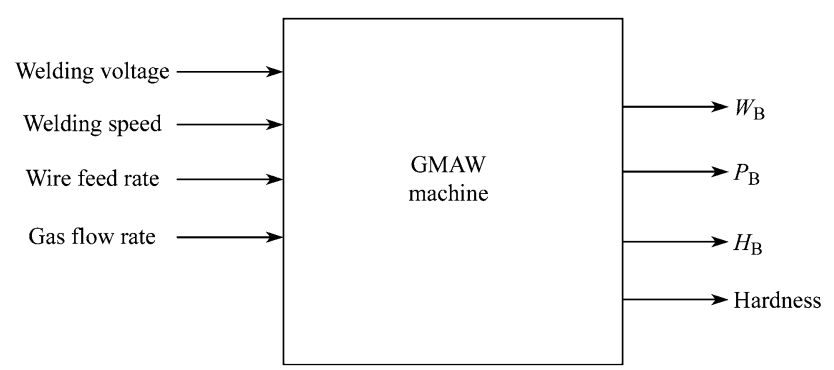

Fig. 3 Input and output process parameters of GMAW

appearance of weld bead without any visible defect and surface porosity. If working ranges of process parameters are lower or above the limits, then proper weld bead will not appear. The upper limits of parameters are coded as +2 and the lower limits are coded as -2 . The coded values for intermediate ranges are calculated using the following equation [15]:

$x_{i}=\frac{2\left(2 x-\left(x_{\max }+x_{\min }\right)\right)}{x_{\max }-x_{\min }}$,

where $x_{i}$ the required coded value of a parameter $x, x$ any value of the parameter from $x_{\max }$ to $x_{\min }, x_{\min }$ the lower level of the parameter, $x_{\max }$ the upper level of the parameter. The levels of the individual process parameters are given in Table 2.

The central composite design matrix [16] is selected which consists of 28 sets of trials. It depends on the number of input process parameters $(k)$. It comprises of sixteen factorial designs $\left(2^{k}\right)$, eight star points $(2 k)$ and four center points. In this case the number of center points is equal to the number of input process parameter $(k)$ or depends on designer for finding the error in the model. The first 16 rows correspond to factorial portion; the rows from 17 to 24 correspond to star point's portion; the last 4 rows from 25 to 28 correspond to center point's position. The final design matrix consists of 28 (i.e., $16+8+4$ ) trials as given in Table 3 .

\subsection{Experimental results}

Twenty-eight experiments are conducted on structural steel plates of AISI321 grade. The experiments are conducted for

Table 2 Process parameters and their values

\begin{tabular}{|c|c|c|c|c|c|c|}
\hline \multirow[t]{2}{*}{ Process parameters } & \multirow[t]{2}{*}{ Notation } & \multicolumn{5}{|c|}{ Limits } \\
\hline & & -2 & -1 & 0 & +1 & +2 \\
\hline Open circuit voltage/V & $V$ & 27 & 28 & 29 & 30 & 31 \\
\hline Wire feed rate $/\left(\mathrm{cm} \cdot \mathrm{min}^{-1}\right)$ & $F$ & 2 & 2.25 & 2.5 & 2.75 & 3.0 \\
\hline Welding speed $/\left(\mathrm{cm} \cdot \mathrm{min}^{-1}\right)$ & $S$ & 20 & 24 & 28 & 32 & 36 \\
\hline Gas flow rate $/\left(\mathrm{L} \cdot \mathrm{min}^{-1}\right)$ & $G$ & 16 & 17 & 18 & 19 & 20 \\
\hline
\end{tabular}

Table 3 Central composite design matrix

\begin{tabular}{|c|c|c|c|c|}
\hline Expt. No. & $\begin{array}{l}\text { Wire feed } \\
\text { rate } \\
i\end{array}$ & $\begin{array}{l}\text { Welding } \\
\text { speed } \\
S\end{array}$ & $\begin{array}{l}\text { Voltage } \\
V\end{array}$ & $\begin{array}{l}\text { Gas flow } \\
\text { rate } \\
G\end{array}$ \\
\hline 1 & -1 & -1 & -1 & -1 \\
\hline 2 & -1 & -1 & -1 & 1 \\
\hline 3 & -1 & -1 & 1 & -1 \\
\hline 4 & -1 & -1 & 1 & 1 \\
\hline 5 & -1 & 1 & -1 & -1 \\
\hline 6 & -1 & 1 & -1 & 1 \\
\hline 7 & -1 & 1 & 1 & -1 \\
\hline 8 & -1 & 1 & 1 & 1 \\
\hline 9 & 1 & -1 & -1 & -1 \\
\hline 10 & 1 & -1 & -1 & 1 \\
\hline 11 & 1 & -1 & 1 & -1 \\
\hline 12 & 1 & -1 & 1 & 1 \\
\hline 13 & 1 & 1 & -1 & -1 \\
\hline 14 & 1 & 1 & -1 & 1 \\
\hline 15 & 1 & 1 & 1 & -1 \\
\hline 16 & 1 & 1 & 1 & 1 \\
\hline 17 & -2 & 0 & 0 & 0 \\
\hline 18 & 2 & 0 & 0 & 0 \\
\hline 19 & 0 & -2 & 0 & 0 \\
\hline 20 & 0 & 2 & 0 & 0 \\
\hline 21 & 0 & 0 & -2 & 0 \\
\hline 22 & 0 & 0 & 2 & 0 \\
\hline 23 & 0 & 0 & 0 & -2 \\
\hline 24 & 0 & 0 & 0 & 2 \\
\hline 25 & 0 & 0 & 0 & 0 \\
\hline 26 & 0 & 0 & 0 & 0 \\
\hline 27 & 0 & 0 & 0 & 0 \\
\hline 28 & 0 & 0 & 0 & 0 \\
\hline
\end{tabular}

two pass bead on steel plates using AISI308 stainless steel filler wire rod of $1.2 \mathrm{~mm}$ diameter and $10 \mathrm{~mm}$ thickness material filled in minimum passes. Experiments are carried out under the shield of a mixture of argon and oxygen gas. The flow rate of shielding gas is in the range of $16-20 \mathrm{~L} / \mathrm{min}$. The samples prepared after welding are shown in Fig. 4.

Each of these samples after welding is cut into three parts for the measurement of bead geometry parameters, hardness, tensile strength and microstructure. Sample preparation was done as per ASTM E 3-11 standard. The measured values of $H_{\mathrm{B}}, W_{\mathrm{B}}$ and $P_{\mathrm{B}}$ and hardness are given in Table 4.

The sectional views at $20 \mathrm{X}$ magnification of welded sample 2, sample 15 and sample 24 are shown in Fig. 5.

\subsection{Development of mathematical models}

The experiments are conducted as per central composite design matrix to develop the mathematical models for 


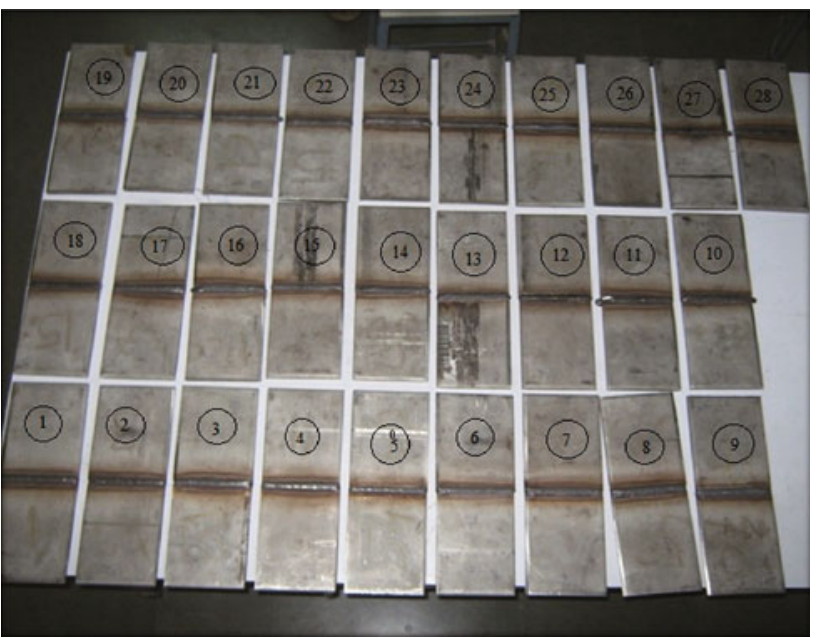

Fig. 4 Samples after the experimental

Table 4 Experimental results

\begin{tabular}{|c|c|c|c|c|}
\hline Expt. No. & $H_{\mathrm{B}} / \mathrm{mm}$ & $W_{\mathrm{B}} / \mathrm{mm}$ & $P_{\mathrm{B}} / \mathrm{mm}$ & Hardness/HV \\
\hline 1 & 3.05 & 10.41 & 8.41 & 172 \\
\hline 2 & 3.43 & 11.16 & 9.95 & 178 \\
\hline 3 & 3.31 & 11.81 & 8.96 & 175 \\
\hline 4 & 4.16 & 11.92 & 8.34 & 173 \\
\hline 5 & 1.86 & 11.07 & 7.21 & 174 \\
\hline 6 & 2.84 & 10.31 & 8.26 & 176 \\
\hline 7 & 2.10 & 10.13 & 8.60 & 177 \\
\hline 8 & 3.18 & 11.22 & 8.97 & 175 \\
\hline 9 & 3.65 & 12.91 & 8.95 & 174 \\
\hline 10 & 3.79 & 10.87 & 8.94 & 173 \\
\hline 11 & 4.76 & 11.96 & 8.75 & 175 \\
\hline 12 & 3.66 & 13.31 & 8.12 & 172 \\
\hline 13 & 2.84 & 12.55 & 7.06 & 175 \\
\hline 14 & 2.37 & 11.31 & 8.67 & 177 \\
\hline 15 & 4.81 & 11.85 & 8.63 & 174 \\
\hline 16 & 2.83 & 11.80 & 8.99 & 174 \\
\hline 17 & 2.73 & 10.88 & 7.85 & 176 \\
\hline 18 & 3.03 & 10.96 & 8.76 & 172 \\
\hline 19 & 4.34 & 12.69 & 8.54 & 176 \\
\hline 20 & 2.30 & 10.40 & 7.81 & 174 \\
\hline 21 & 1.92 & 10.16 & 7.76 & 177 \\
\hline 22 & 4.83 & 11.97 & 9.07 & 173 \\
\hline 23 & 2.51 & 12.11 & 8.71 & 175 \\
\hline 24 & 3.67 & 13.15 & 8.97 & 172 \\
\hline 25 & 2.41 & 11.10 & 8.26 & 178 \\
\hline 26 & 2.49 & 11.65 & 8.28 & 176 \\
\hline 27 & 2.56 & 11.48 & 8.87 & 177 \\
\hline 28 & 2.47 & 11.94 & 8.66 & 175 \\
\hline
\end{tabular}

showing the relationships between the output responses $y\left(H_{\mathrm{B}}, W_{\mathrm{B}}\right.$ and $\left.P_{\mathrm{B}}\right)$ and input parameters $x$ (welding voltage, wire feed rate, welding speed and gas flow rate).

The second order response surface model for the four selected parameters is given by the equation [17]:

$y=b_{0} \sum_{i=1}^{4} b_{i} x_{i}+\sum_{i=1}^{4} b_{i i} x_{i}^{2}+\sum_{\substack{i, j=1 \\ j \neq i}}^{4} b_{i j} x_{i} x_{j}$.

For four parameters, the selected polynomial could be expressed as:

$$
\begin{aligned}
y= & b_{0}+b_{1} S+b_{2} V+b_{3} F+b_{4} G+b_{11} S^{2}+b_{22} V^{2} \\
& +b_{33} F^{2}+b_{44} G^{2}+b_{12} S V+b_{13} S F+b_{14} S G+b_{23} V F \\
& +b_{24} V G+b_{34} F G,
\end{aligned}
$$

where $b_{0}$ the free term of regression equation, $b_{1}, b_{2}, \cdots, b_{k}$ the linear terms, $b_{11}, \mathrm{~b}_{22}, \cdots, b_{k k}$ the quadratic terms and $b_{12}, b_{13}, \cdots, b_{k-1 k}$ the interaction terms.

To test the goodness of fit of the developed models, adequacy is determined by the analysis of variance technique (ANOVA) to evaluate the statistical significance of the fitted models and variables involved therein for response parameters like $W_{\mathrm{B}}, H_{\mathrm{B}}$ and $P_{\mathrm{B}}$. The goodness of fit of the models is also evaluated through "lack of fit test". The probability which is greater than $F$ is found in excess of 0.05 , implying that the lack of fit is insignificant. The probability of values which are greater than $F$ is less than 0.05 , which indicate that the contribution of these terms to the model is significant. The ANOVA results for $H_{\mathrm{B}}$ show that $F, S, V, G, S^{2}, V^{2}, F G$ are significant model terms. The ANOVA results for $W_{\mathrm{B}}$ show that $F, S, V, G, G^{2}, V G$ are significant model terms. The ANOVA results for $P_{\mathrm{B}}$ show that $F, S, V, G, S V, S G, V G$ are significant model terms. The values of significant and insignificant coefficients for these model terms are calculated with the help of SYSTAT12 statistical software [18] and given in from Table 5 to Table 7.

One more criterion that is commonly used to illustrate the adequacy of a fitted regression model is the multiple square of $R$ and the adjusted coefficient of determination $\left(R^{2}\right)$. The co-efficient of determination indicates that the data points fit a line or curve. The main purpose of $R^{2}$ is either the prediction of future outcomes or the testing of hypotheses on the basis of other related information. For the developed models the calculated $R^{2}$ and adjusted $R^{2}$ values are given in Table 8 .

These values indicate that the regression models are quite adequate. The final mathematical models in coded form are given below based on ANOVA analysis: 

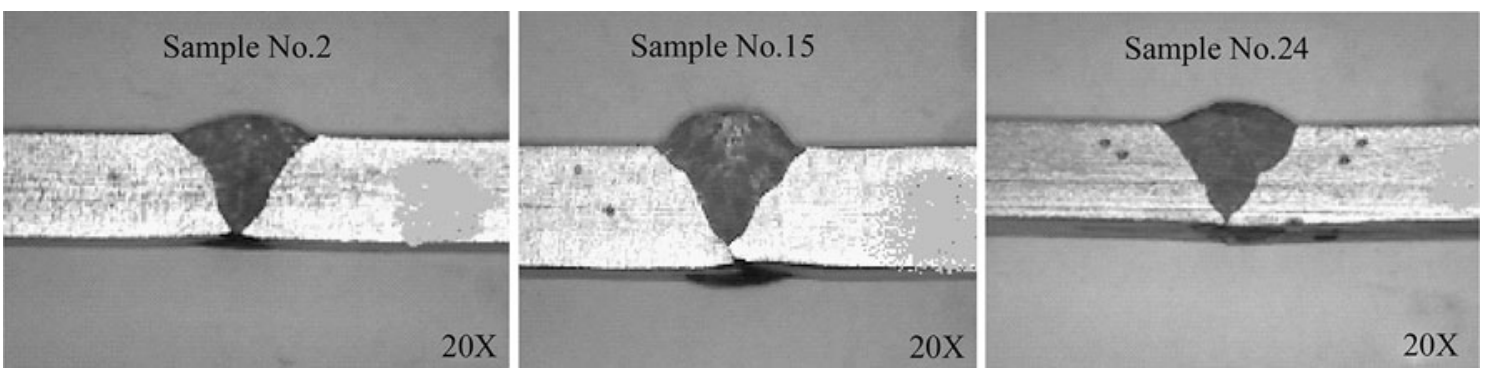

Fig. 5 Sectional views of welded samples

Table 5 Significant and insignificant data for $H_{\mathrm{B}}$

\begin{tabular}{lrlll}
\hline Effects & Coefficients & Standard error & $P$-value & Remarks \\
\hline Constant & 2.483 & 0.242 & 0.000 & Significant \\
$F$ & 0.224 & 0.198 & 0.041 & Significant \\
$S$ & -0.461 & 0.198 & 0.000 & Significant \\
$V$ & 0.450 & 0.198 & 0.001 & Significant \\
$G$ & 0.092 & 0.198 & 0.071 & Significant \\
$F^{2}$ & 0.120 & 0.396 & 0.247 & Not significant \\
$S^{2}$ & 0.230 & 0.396 & 0.037 & Significant \\
$V^{2}$ & 0.244 & 0.396 & 0.028 & Significant \\
$G^{2}$ & 0.172 & 0.396 & 0.105 & Not significant \\
$F S$ & 0.060 & 0.485 & 0.629 & Not significant \\
$S V$ & 0.065 & 0.485 & 0.601 & Not significant \\
$S G$ & -0.041 & 0.485 & 0.739 & Not significant \\
$F V$ & 0.115 & 0.485 & 0.360 & Not significant \\
$V G$ & -0.136 & 0.485 & 0.281 & Not significant \\
$F G$ & -0.419 & 0.485 & 0.004 & Significant \\
\hline
\end{tabular}

Table 6 Significant and insignificant data for $W_{\mathrm{B}}$

\begin{tabular}{lrlll}
\hline Effects & Coefficients & Standard error & $P$-value & Remarks \\
\hline Constant & 11.543 & 0.317 & 0.000 & Significant \\
$F$ & 0.362 & 0.259 & 0.015 & Significant \\
$S$ & -0.362 & 0.259 & 0.015 & Significant \\
$V$ & 0.293 & 0.259 & 0.041 & Significant \\
$G$ & 0.054 & 0.259 & 0.085 & Significant \\
$F^{2}$ & -0.156 & 0.518 & 0.249 & Not significant \\
$S^{2}$ & 0.000 & 0.518 & 0.999 & Not significant \\
$V^{2}$ & -0.120 & 0.518 & 0.371 & Not significant \\
$G^{2}$ & 0.271 & 0.518 & 0.056 & Significant \\
$F S$ & 0.064 & 0.634 & 0.691 & Not significant \\
$S V$ & -0.243 & 0.634 & 0.149 & Not significant \\
$S G$ & -0.071 & 0.634 & 0.663 & Not significant \\
$F V$ & -0.053 & 0.634 & 0.743 & Not significant \\
$V G$ & 0.362 & 0.634 & 0.040 & Significant \\
$F G$ & -0.198 & 0.634 & 0.233 & Not significant \\
\hline
\end{tabular}

Table 7 Significant and insignificant data for $P_{\mathrm{B}}$

\begin{tabular}{lclll}
\hline Effects & Coefficients & Standard error & $P$-value & Remarks \\
\hline Constant & 8.517 & 0.185 & 0.000 & Significant \\
$F$ & 0.051 & 0.151 & 0.051 & Significant \\
$S$ & -0.229 & 0.151 & 0.010 & Significant \\
$V$ & 0.189 & 0.151 & 0.027 & Significant \\
$G$ & 0.175 & 0.151 & 0.038 & Significant \\
$F^{2}$ & -0.034 & 0.302 & 0.663 & Not significant \\
$S^{2}$ & -0.066 & 0.302 & 0.397 & Not significant \\
$V^{2}$ & -0.006 & 0.302 & 0.936 & Not significant \\
$G^{2}$ & 0.100 & 0.302 & 0.208 & Not significant \\
$F S$ & 0.076 & 0.370 & 0.428 & Not significant \\
$S V$ & 0.379 & 0.370 & 0.001 & Significant \\
$S G$ & 0.194 & 0.370 & 0.056 & Significant \\
$F V$ & -0.011 & 0.370 & 0.910 & Not significant \\
$V G$ & -0.294 & 0.370 & 0.007 & Significant \\
$F G$ & -0.093 & 0.370 & 0.507 & Not significant \\
\hline
\end{tabular}

$$
\begin{aligned}
P_{\mathrm{B}}= & 8.517+0.051 F-0.229 S+0.189 V+0.175 G \\
& +0.379 S V+0.194 S G-0.294 V G \\
H_{\mathrm{B}}= & 2.483+0.224 F-0.461 S+0.450 V+0.092 G+0.230 S^{2} \\
& +0.244 V-0.419 F G \\
W_{\mathrm{B}}= & 11.543+0.362 F-0.362 S+0.293 V+0.054 G \\
& +0.271 G^{2}+0.362 V G .
\end{aligned}
$$

Similarly, the final mathematical models in uncoded form based on the ANOVA analysis are given below:

$$
\begin{aligned}
P_{\mathrm{B}}= & -51.174+0.205 F-3.682 S+2.832 V+7.351 G \\
& +0.095 S V+0.049 S G-0.294 V G \\
H_{\mathrm{B}}= & 77.941+31.047 F-0.715 S-10.294 V+4.279 G \\
& +0.011 S^{2}+0.185 V^{2}-1.675 F G \\
W_{\mathrm{B}}= & 292.436+1.448 F-0.091 S-6.221 V-21.865 G \\
& +0.317 G^{2}+0.362 V G .
\end{aligned}
$$


Table 8 ANOVA for model developed

\begin{tabular}{|c|c|c|c|c|c|c|c|c|c|c|}
\hline \multirow[t]{2}{*}{ Bead geometry } & \multicolumn{2}{|c|}{ Sum of the square } & \multicolumn{2}{|c|}{ Degree of freedom } & \multicolumn{2}{|c|}{ Mean square } & \multirow[t]{2}{*}{$F$ ratio } & \multirow[t]{2}{*}{$P$} & \multirow[t]{2}{*}{$R^{2} / \%$} & \multirow[t]{2}{*}{ Adjusted $R^{2} / \%$} \\
\hline & Residual & Regression & Residual & Regression & Residual & Regression & & & & \\
\hline$P_{\mathrm{B}}$ & 7.199 & 7.854 & 7 & 14 & 0.561 & 1.028 & 4.102 & 0.008 & 81 & 61 \\
\hline$W_{\mathrm{B}}$ & 13.279 & 15.878 & 6 & 14 & 1.134 & 2.213 & 2.821 & 0.035 & 75 & 48 \\
\hline$H_{\mathrm{B}}$ & 15.628 & 17.154 & 7 & 14 & 1.225 & 2.233 & 5.217 & 0.003 & 84 & 68 \\
\hline
\end{tabular}

Tabulated values of $F: F_{0.05}(7,14)=2.76, F_{0.05}(6,14)=2.81$

To verify the regression equations, two experiments were conducted using different values of input process parameters which are in the ranges but other than the values used in the design matrix. The output responses measured and the predicted results obtained are presented in Table 9. It is observed that the percentage error obtained between the measured and predicted values are quite small and the verification is satisfactory.

\section{Effects of process parameters on bead geometry parameters, hardness and microstructure}

The mathematical models developed after the experimental for $H_{\mathrm{B}}, W_{\mathrm{B}}, P_{\mathrm{B}}$ can be employed to predict the geometry of weld bead and hardness. The effects of individual welding parameters and their joint effects on all the bead geometry parameters and hardness are calculated quantitatively and analyzed. The main joint effects of welding parameters on various response parameters are presented graphically for quick analyses.

\subsection{Direct effects of input process parameters}

\subsubsection{Effect of process parameters on $W_{\mathrm{B}}$}

From Fig. 6 it is apparent that $W_{\mathrm{B}}$ increases with the increase in $G, V$ and $F$, whereas it decreases with the increase in $S$. The increase in the welding voltage produces flatter, wider, less penetrated weld beads. The increase in the voltage also increases the size of droplets and hence decreases the number of droplets. The increase in $F$ increases the amount of metal deposited and therefore
$W_{\text {B }}$ will increase. The increase in $G$ produces high velocity which causes filler metals more melting and results in increase in $W_{\mathrm{B}}$. At high welding speed, the volume of metal deposited decreases and also the heat input per unit length reduces.

\subsubsection{Effect of process parameters on $H_{\mathrm{B}}$}

It is observed from Fig. 7 that $H_{\mathrm{B}}$ decreases with the increase in $S$ and $F$ whereas it increases with the increase in $G$ and $V$. The less amount of metal per unit length is deposited on the base metal with the increase in $S$ which will reduce the $H_{\mathrm{B}}$. The melting of base metal will be more when $V$ increases, resulting in slightly increase of $H_{\mathrm{B}}$. Increase in $G$ produces high velocity plasma, resulting in an increase in fusion area and $H_{\mathrm{B}}$. Increase in $F$ will deposit less molten metal above the base metal and hence decreases the $H_{\mathrm{B}}$.

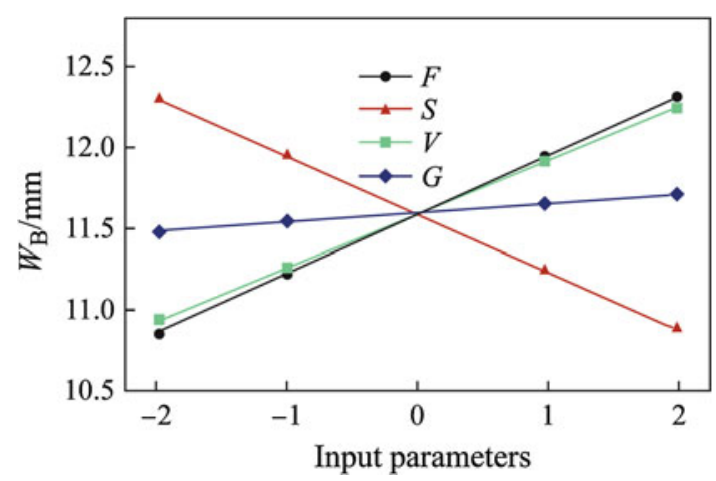

Fig. 6 Effect of input parameters on $W_{\mathrm{B}}$

Table 9 Result of confirmation test

\begin{tabular}{|c|c|c|c|c|c|c|c|c|c|}
\hline \multirow[t]{2}{*}{ Expt. No. } & \multicolumn{3}{|c|}{ Measured values } & \multicolumn{3}{|c|}{ Predicted values } & \multicolumn{3}{|c|}{ Error/\% } \\
\hline & $H_{\mathrm{B}}$ & $W_{\mathrm{B}}$ & $P_{\mathrm{B}}$ & $H_{\mathrm{B}}$ & $W_{\mathrm{B}}$ & $P_{\mathrm{B}}$ & $H_{\mathrm{B}}$ & $W_{\mathrm{B}}$ & $P_{\mathrm{B}}$ \\
\hline CON1 & 3.57 & 12.56 & 8.90 & 3.53 & 12.87 & 9.15 & 1.10 & -2.40 & -2.73 \\
\hline CON2 & 3.86 & 11.23 & 9.46 & 3.82 & 11.69 & 9.26 & 1.04 & -3.93 & 2.15 \\
\hline
\end{tabular}

Error $=\frac{\text { Measured value-Predicted value }}{\text { Predicted value }} \times 100 \%$ 


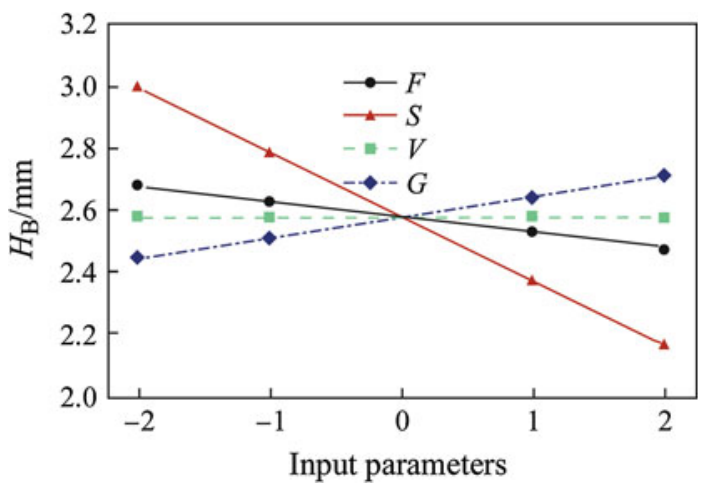

Fig. 7 Effect of input parameters on $H_{\mathrm{B}}$

\subsubsection{Effect of process parameters on $P_{\mathrm{B}}$}

It is found from Fig. 8 that $P_{\mathrm{B}}$ is indirectly proportional to $S$ and directly proportional to $V, G$ and $F . P_{\mathrm{B}}$ decreases with the increase in welding speed because the time during which the arc force is allowed to penetrate into the material's surface decreases. $P_{\mathrm{B}}$ increases with the increase in $G$ which fills the material into the weld bead groove and gives more penetration inside the groove. Increase in $V$ and $F$ will deposit more molten metal inside the groove and will increase the $P_{\mathrm{B}}$.

\subsubsection{Effect of process parameters on hardness}

Vickers hardness tests are conducted at different zones of the weldment as per ASTM E 384 standards. These include weld zone, heat affected zone (HAZ) and base metal. The average values are calculated and given in Table 4. The average values obtained using Vickers hardness test after experimental are in the range of standard values of the hardness of the AISI 321 steel.

From Fig. 9 it is observed that with the increases in $V, F$, $G$ and the value of hardness increases. Hardness decreases with the increasing of $S$. The hardness in weld zone and HAZ is due to over precipitation and increased carbon

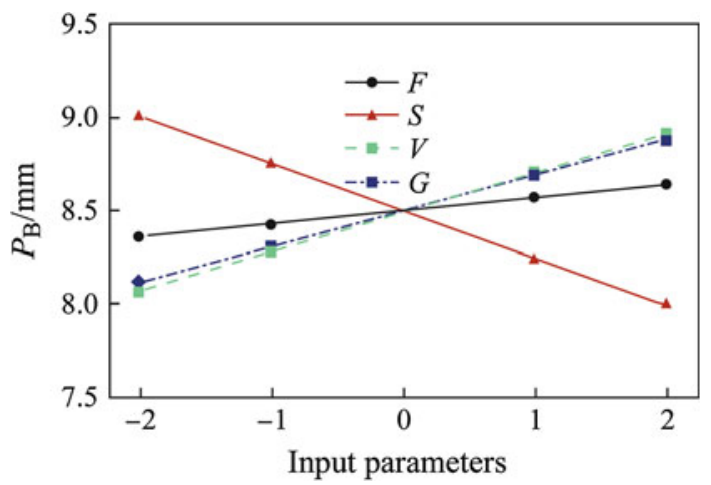

Fig. 8 Effect of input process parameters on $P_{\mathrm{B}}$

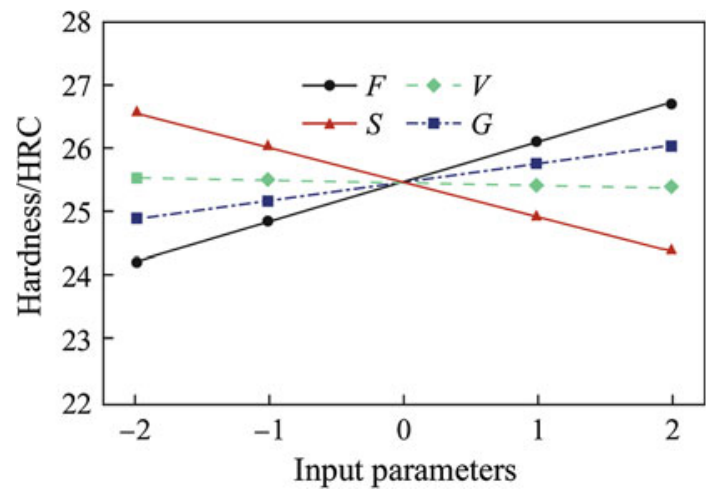

Fig. 9 Effect of input process parameters on hardness

precipitation amount. If hardness gets too high, the weld strength will be high and the ductility will be very low. The hardness decreases at a distance away from HAZ.

\subsection{Joint effects of input process parameters}

\subsubsection{Joint effect of wire feed rate and gas flow rate on $H_{\mathrm{B}}$}

Figure 10 shows the joint effect of $F$ and $G$ on $H_{\mathrm{B}}$. It is evident that $H_{\mathrm{B}}$ remains the same with the decrease in gas flow rate for zero level of wire feed rate. The regions with various welds $H_{\mathrm{B}}$ for different combinations of $F$ and $G$ are depicted in Fig. 10, which shows that $H_{\mathrm{B}}$ decreases with increase in $F$ and decrease in $G$.

\subsubsection{Joint effect of welding speed and gas flow rate on $P_{\mathrm{B}}$}

Figure 11 shows the joint effect of $S$ and $G$ on $P_{\mathrm{B}}$. It is observed that $P_{\mathrm{B}}$ increases slightly with the increase in gas flow rate for all levels of welding speed but it is also evident that $P_{\mathrm{B}}$ slightly decreases with the increase in welding speed for all levels of gas flow rate.

\subsubsection{Joint effect of welding speed and voltage on $P_{\mathrm{B}}$}

Figure 12 shows the joint effect of $S$ and $V$ on $P_{\mathrm{B}}$. It is clear from Fig. 12 that $P_{\mathrm{B}}$ remains the same with the increase in

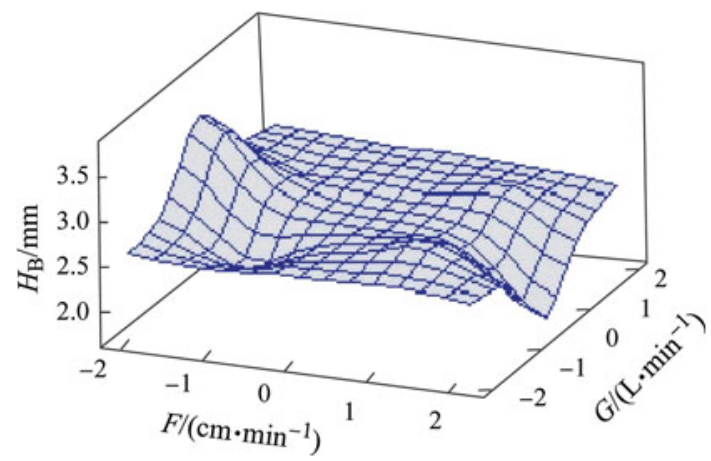

Fig. 10 Interactive surface plot of $H_{\mathrm{B}}$ versus $F$ and $G$ 


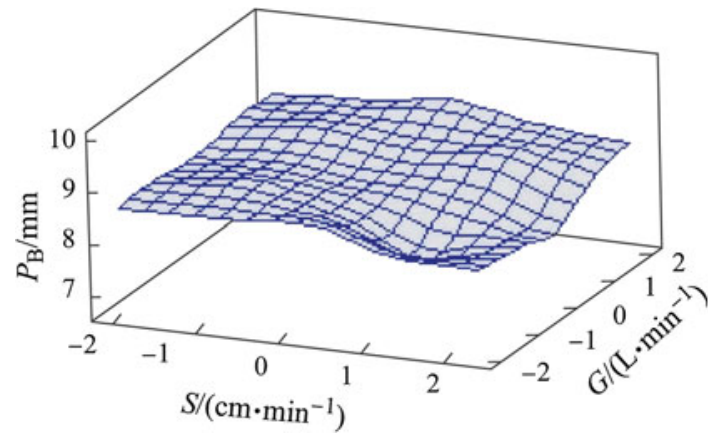

Fig. 11 Interaction surface plot of $P_{\mathrm{B}}$ versus $S$ and $G$

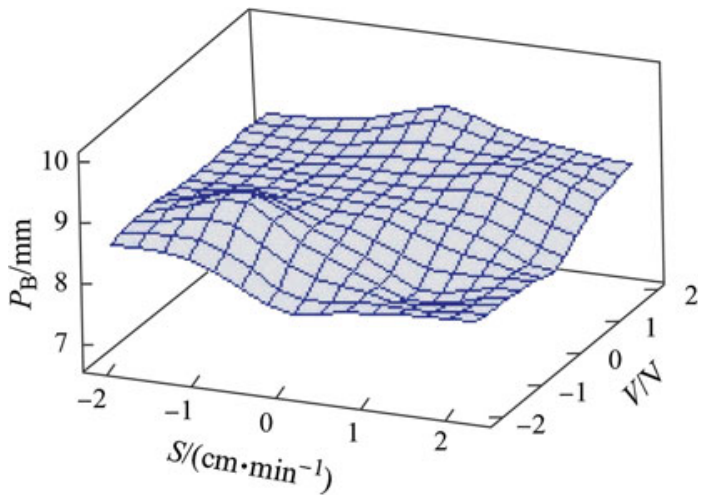

Fig. 12 Interaction surface plot of $P_{\mathrm{B}}$ versus $S$ and $V$

welding voltage for zero level of welding speed and $P_{\mathrm{B}}$ decreases with the increase in welding speed at zero levels of welding voltage.

\subsubsection{Joint effect of welding voltage and gas flow rate on $P_{\mathrm{B}}$}

Figure 13 shows the joint effect of $V$ and $G$ on $P_{\mathrm{B}}$. It is clear that the $P_{\mathrm{B}}$ increases with increase in gas flow rate for all levels of $G$. In addition, $P_{\mathrm{B}}$ increases with the increasing of $V$. Therefore, $G$ and $V$ can both be used to change the weight of metal deposited per unit bead length.

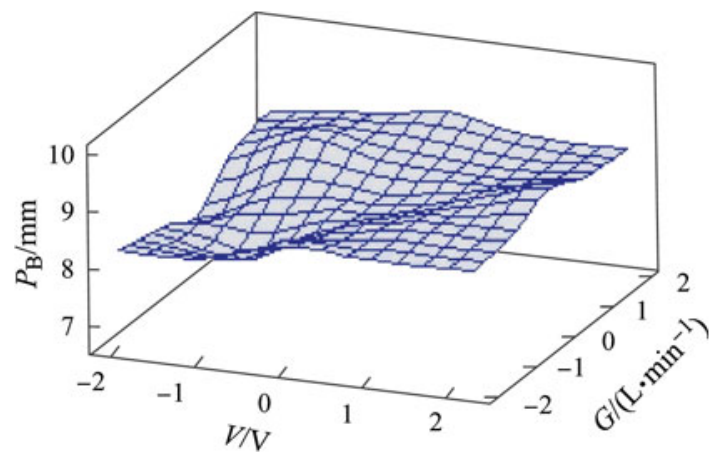

Fig. 13 Interaction surface plot of $P_{\mathrm{B}}$ versus $V$ and $G$

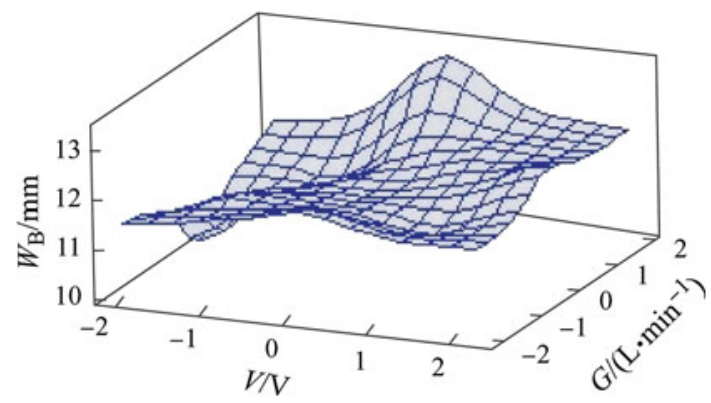

Fig. 14 Interaction surface plot of $W_{\mathrm{B}}$ versus $V$ and $G$

\subsubsection{Joint effect of welding voltage and gas flow rate on $W_{\mathrm{B}}$}

Figure 14 shows the joint effect of $V$ and $G$ on $W_{\mathrm{B}}$. It is clear that the $H_{\mathrm{B}}$ increases with the increase in welding voltage for all levels of $G$, whereas $W_{\mathrm{B}}$ decreases with the decrease in $G$ for all levels of $V$.

\subsection{Effect of input process parameters on microstructure}

The microstructures at the base metal, weld zone and HAZ regions predict the mechanical properties of a weldment such as hardness, strength and toughness. In multipass GMAW process there is an inadequate transfer of heat in the weld zone, HAZ and the base metal, therefore it is necessary to control the microstructure at various phases by controlling the welding parameters. In welded regions microstructure contains grain boundary of ferrite, pearlite, bainite and martensite depending on the cooling rate. Welding parameters, heat input, alloying elements, filler material and dilution are the sole variables to control the bead geometry, mechanical properties and microstructure. The metallurgical features that are directly affected by heat input rate are the grain sizes and the amount of ferrite, pearlite, bainite and martensite in the heat affected and the weld zones [19]. In multipass welds partial or complete recrystallization of weld metal occurs, depending upon the heat input, bead dimensions and the time interval between successive depositions [20]. The structure is refined with a corresponding improvement in ductility and toughness. In fusion zone entire metal has been melted and solidified in each pass. During cooling of the weldment, it undergoes certain changes of chemical, physical or structural nature. The thermal cycle and actual nature of the alloy decide whether it is hardenable, sensitive to phase changes by precipitation, austenitic, and so on.

Optical microscopy of $100 \mathrm{X}$ magnification is used and ASTM E 407 standards are followed mainly to evaluate the microstructure in different zones of the weldments. The joints are filled with two passes and the multipass welded 


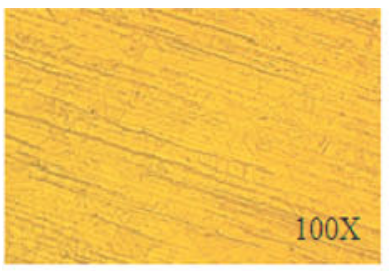

Sample 3(base metal)

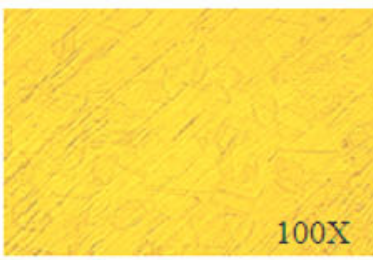

Sample 8(base metal)

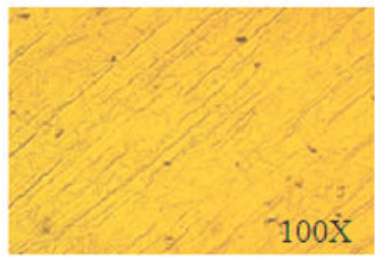

Sample 13(base metal)

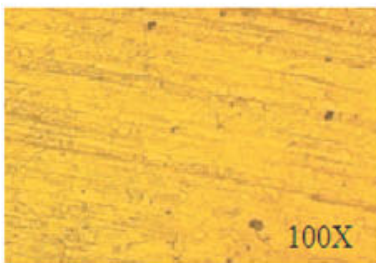

Sample 17(base metal)

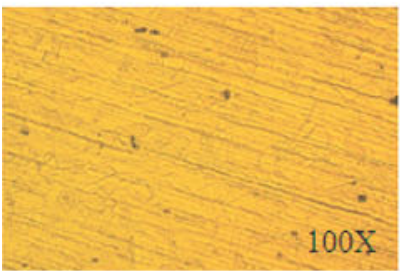

Sample 21(base metal)

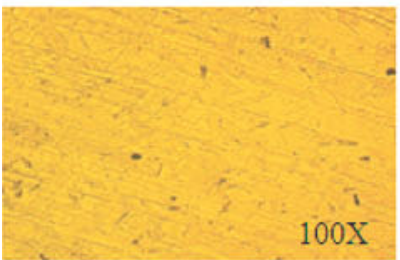

Sample 25(base metal)

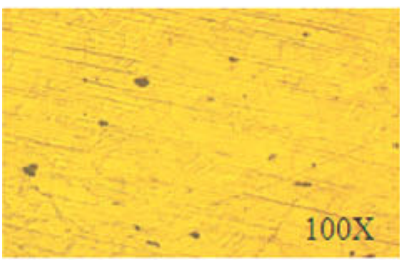

Sample 28(base metal)

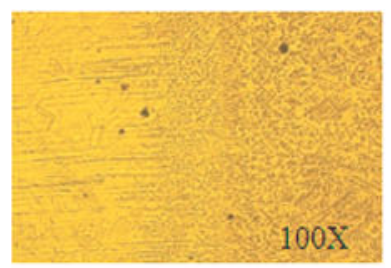

Sample 3(HAZ)

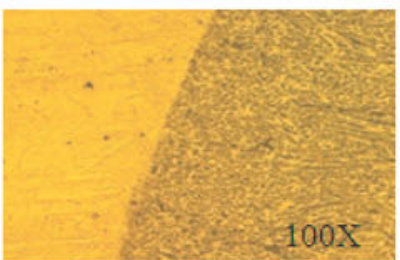

Sample 8(HAZ)

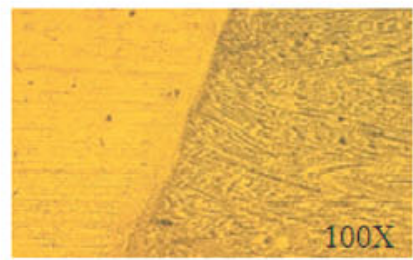

Sample 13(HAZ)

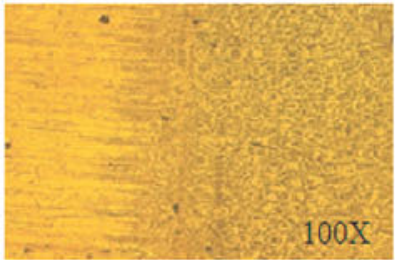

Sample 17(HAZ)

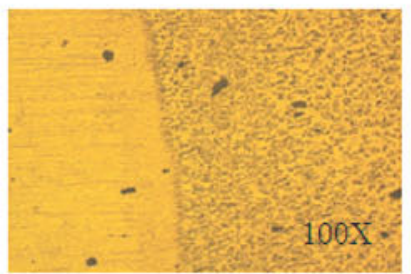

Sample 21(HAZ)

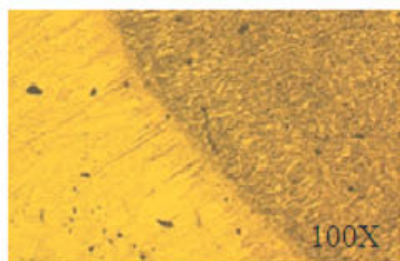

Sample 25(HAZ)

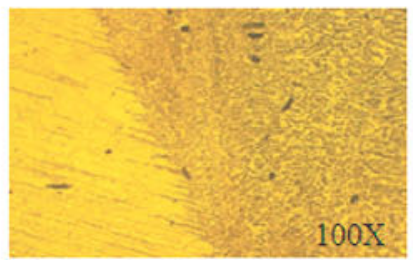

Sample 28(HAZ)

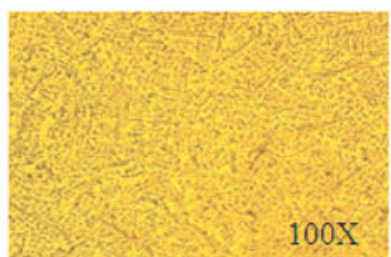

Sample 3(weld zone)

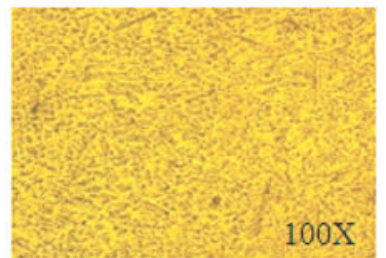

Sample 8(weld zone)

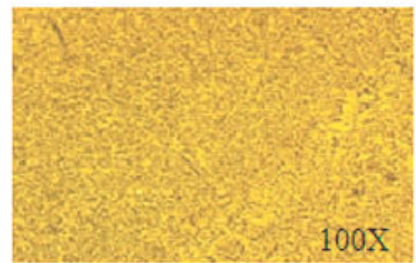

Sample 13(weld zone)

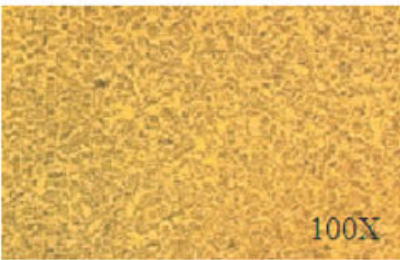

Sample 17(weld zone)

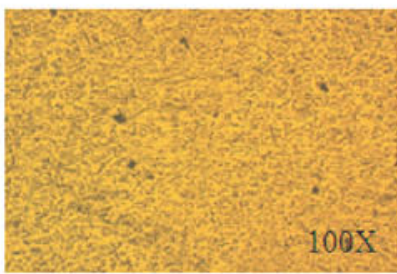

Sample 21(weld zone)

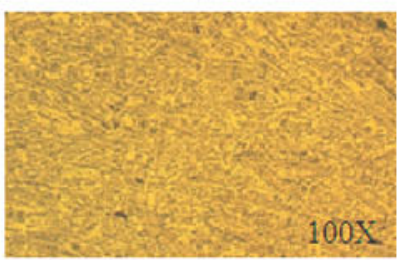

Sample 25(weld zone)

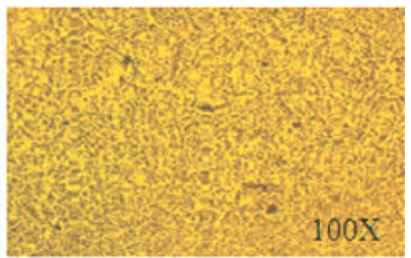

Sample 28(weld zone)

Fig. 15 Microstructure of welded part at three areas of the weldment 
specimens are cut and molded in backelite powder for easy handling during automatic grinding and polishing. The machined surfaces are abraded successively using finer grades of waterproof silicon carbide papers $(100,220,400$, 600 and 800). The velvet cloth and wet alumina powder of mesh size $0.023 \mu \mathrm{m}$ are used for polishing. The specimens are finally immersed in an etchant (10\% oxalic acid) and the etching is done by electrolytic method until good structures are obtained. The microstructure of some welded samples taken at three different zones of weldment viz: i) at the base material, ii) at the HAZ, iii) at the weld zone, as shown in Fig. 15. It is observed that base metal structure has not been affected away from the weld. Microstructures are observed in pearlite and ferrite phase. Polygonal and equiaxed white grains of ferrite occupy about $99.5 \%$ volume and the rest dark phase is resolved pearlite. Annealing twins are observed. Deformation bands parallel to rolling direction are also observed. HAZ revealed coarse grain structure on one side and cast structure on the other side due to the transient effects. The weld zone shows typical cast structure and directionally solidified columnar dendrites are observed.

\section{Transient thermal analysis of AISI 321 weldment}

Heat flow during welding controls the fusion size as well as affects the properties of the weldment. The temperature distribution plays an important role in changing the properties of the weldment. Thermal stresses are induced during a heating or cooling process and transient stresses are due to a non-uniform temperature gradient [21]. Thermal stresses are directly combined with mechanical stresses that are used for components design. Heat transfers are

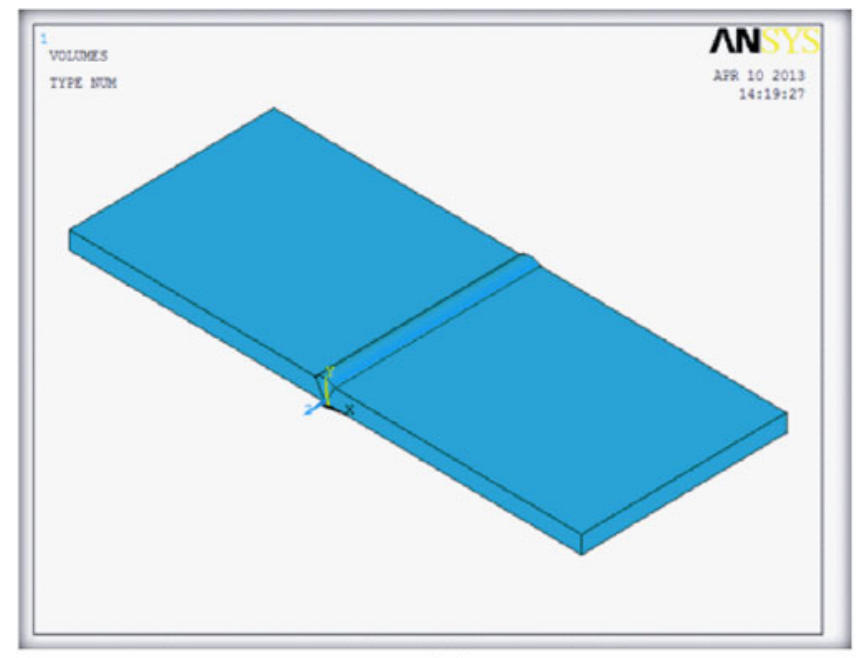

(a) divided into three basic modes viz: conduction, convection and radiation. Conduction refers to the transfer of heat through a solid or non-moving fluid. The rate of heat in conduction is directly proportional to the area and inversely proportional to the length, i.e., the smaller the cross section, the faster the rate, and the longer the path, the slower the rate. Convection is the transfer of heat through a fluid where the fluid is moving. It can be forced when one fluid is pumped over a surface or free when fluid circulates due to convection currents alone. In finite element method (FEM) problems, convection is used as a boundary condition where the surface temperatures are unknown quantities. Radiation is the transfer of heat either through a vacuum or air. Radiation and convection may take place simultaneously or independently between two surfaces. It can be predominant at high temperatures and also requires a non-linear formulation.

The numerical study of thermally induced residual stresses [22] was carried out. The simulations are performed on welded plate of size $300 \mathrm{~mm} \times 120 \mathrm{~mm} \times 10 \mathrm{~mm}$ made of $60^{\circ}$ groove angle and jointing together using GMAW process. The height of the semi circular bead has been considered as $2 \mathrm{~mm}$ and the developed model is shown in Fig. 16a. The density of the material is considered to be constant within the temperature range and taken as $2,900 \mathrm{~kg} / \mathrm{m}^{3}$, specific heat as $500 \mathrm{~J} /(\mathrm{kg} \cdot \mathrm{K})$, modulus of elasticity as $210 \mathrm{GPa}$ and poisson's ratio as 0.3 . The thermal properties of AISI 321 grade steel are listed in Table 10. The meshing for thermal environment is chosen as "Brick 8 node 70 " or SOLID70 type and it has three dimensional (3-D) thermal conduction capabilities. The element has eight nodes with a single degree of freedom (DoF) at each node. The element is applicable to solve a 3-D steady state or transient thermal analysis. If the model containing the conducting solid

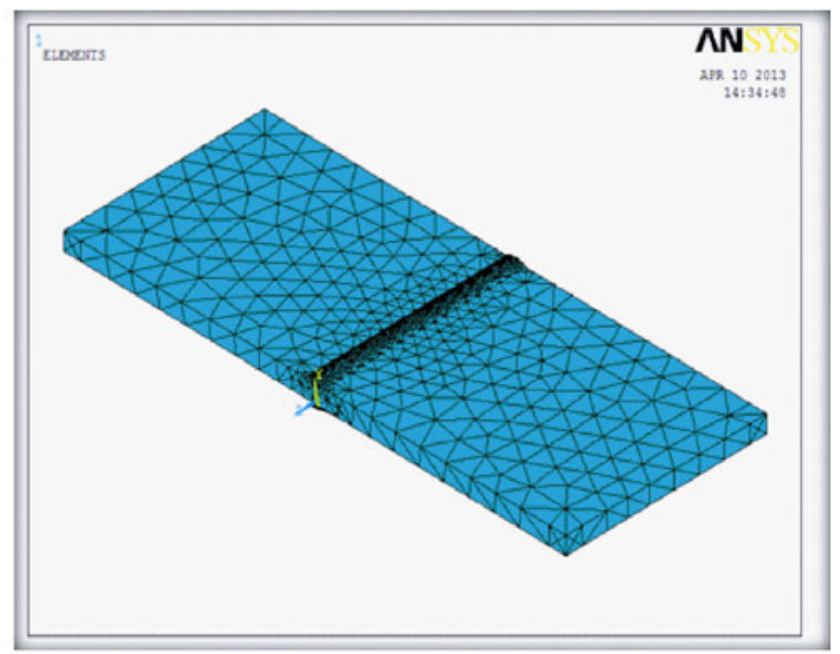

(b)

Fig. 16 a Model developed and $\mathbf{b}$ Meshing of the model 
Table 10 Thermal properties of AISI321 steel

\begin{tabular}{lllllll}
\hline & \multicolumn{7}{c}{ Temperature/K } & & & \\
\cline { 2 - 7 } & 373 & 473 & 573 & 673 & 773 & 873 \\
\hline $\begin{array}{l}\text { Thermal conductivity/ } \\
\left(\mathrm{W} \cdot \mathrm{m}^{-1} \cdot \mathrm{K}^{-1}\right)\end{array}$ & 16.1 & 17.0 & 18.2 & 20.4 & 22.2 & 22.5 \\
$\begin{array}{l}\text { Thermal expansion } \\
\text { coefficient/ } \\
\left(10^{-6} \cdot \mathrm{m}^{-1} \cdot \mathrm{K}^{-1}\right)\end{array}$ & 16.0 & 16.5 & 17 & 17.5 & 18 & 18.6 \\
\hline
\end{tabular}

element is also to be analyzed structurally, the element should be replaced by an equivalent structural element such as SOLID185 and the meshed model developed is shown in Fig. 16b. The thermal boundary condition means the temperature difference at the two points viz: at the middle of the weldment and at the end of the weldment. The temperature at the middle part is assumed as $1,425^{\circ} \mathrm{C}$ (i.e., melting point temperature of AISI 308) and the temperature at the end of the model is assumed as $28{ }^{\circ} \mathrm{C}$ (i.e., room temperature). The thermal boundary environment is converted into structural environment, i.e., SOLID70 element is converted into SOLID185 structural element. The plates are clamped at both the ends of the plate, and the movements are restricted in the $y$ and $z$ directions and allowed along the $x$ direction when stresses are developed during welding.

In transient thermal analysis, temperature varies at different time at different points in the weldment zone. Therefore, temperature distribution at four different time steps viz: $10 \mathrm{~s}, 58 \mathrm{~s}, 202 \mathrm{~s}$ and 1,000 s due to conduction and convections are shown in Figs. 17 and 18 respectively. It is observed from Fig. 17 that high temperature exits in the welded zone and temperature distributed along the length of the weldment. After $1,000 \mathrm{~s}$ the temperature distributes up to the end of the weldment due to

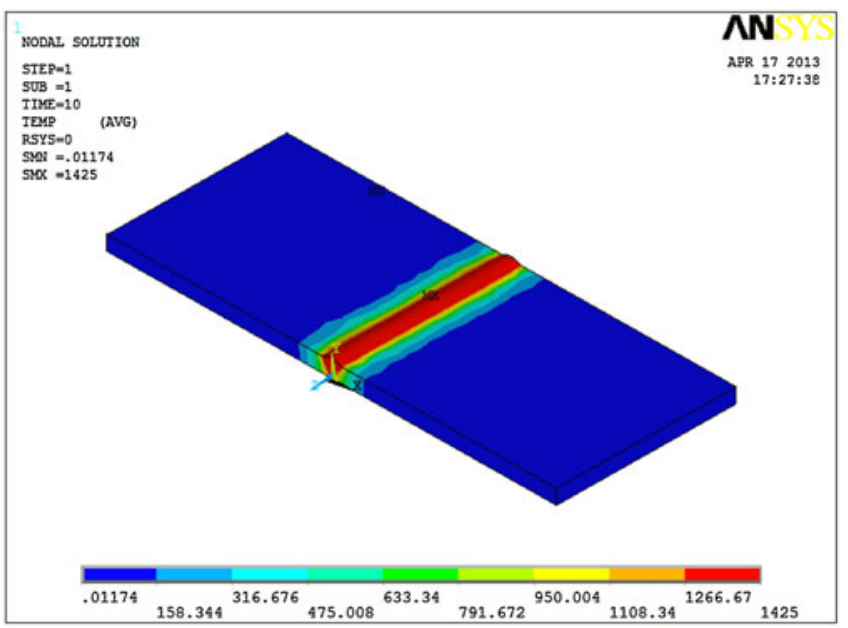

(a)

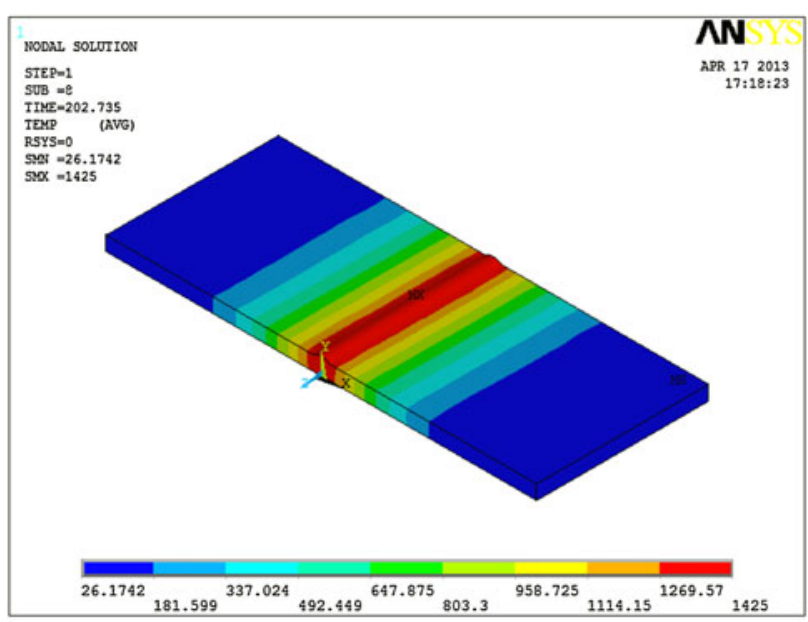

(c)

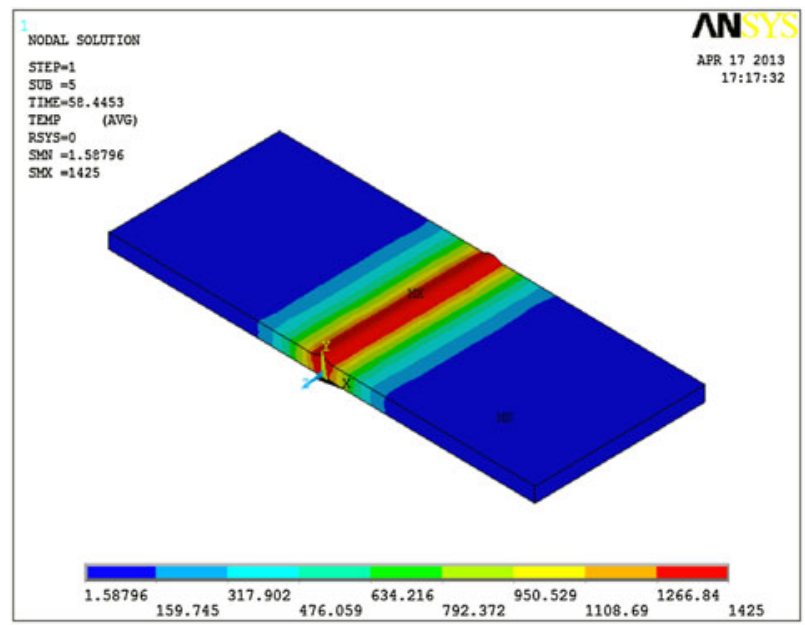

(b)

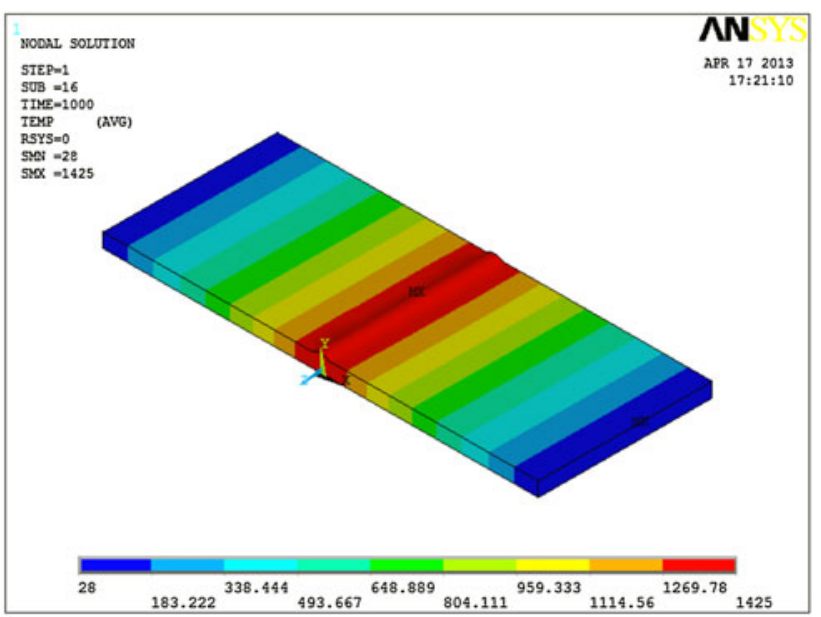

(d)

Fig. 17 Temperature distributions along plate due to conduction at different time. a at $t=10 \mathrm{~s}, \mathbf{b}$ at $t=58 \mathrm{~s}, \mathbf{c}$ at $t=202 \mathrm{~s}, \mathbf{d}$ at $t=1000 \mathrm{~s}$ 


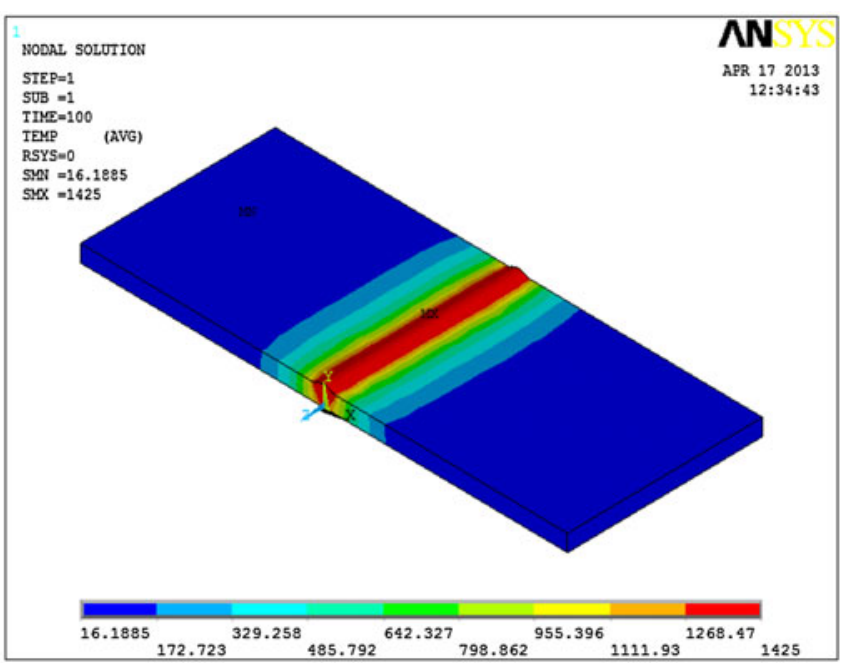

(a)

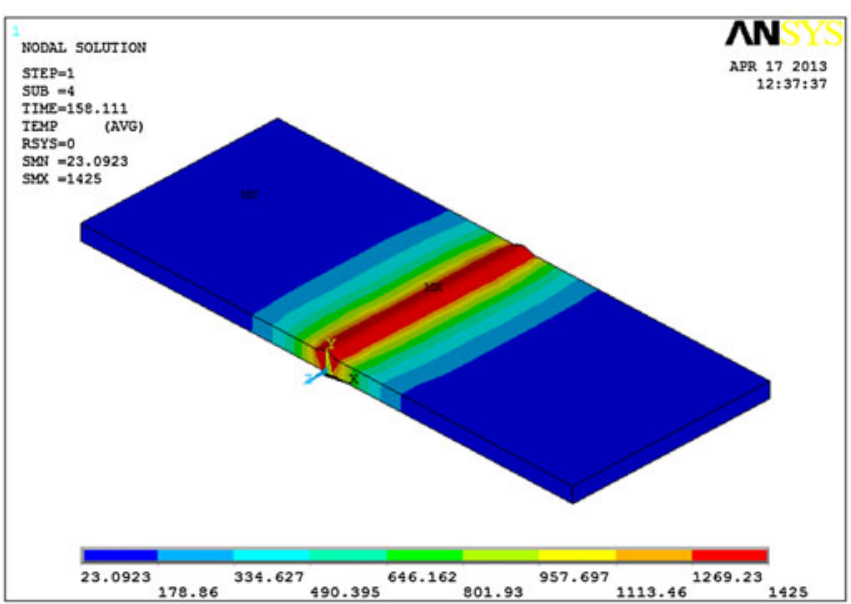

(c)

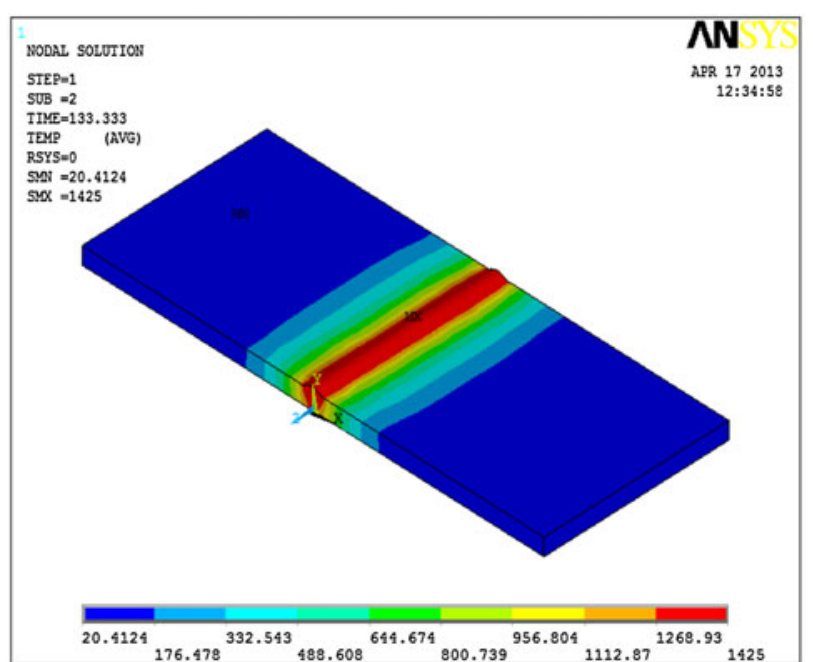

(b)

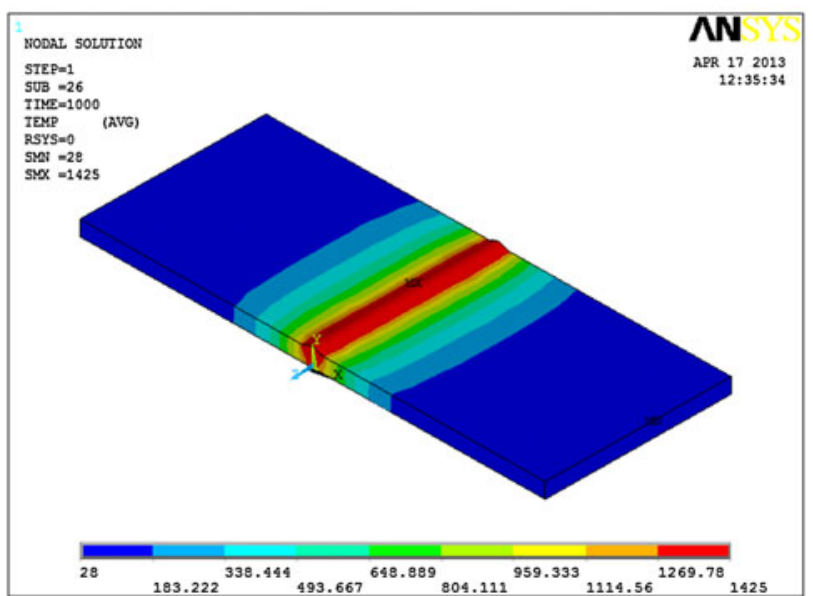

(d)

Fig. 18 Temperature distributions along plate due to convection at different time. a at $t=10 \mathrm{~s}, \mathbf{b}$ at $t=58 \mathrm{~s}, \mathbf{c}$ at $t=202 \mathrm{~s}, \mathbf{d}$ at $t=1000 \mathrm{~s}$

conduction. Figure 17 shows that the temperature distribution due to convection in the middle part of the weldment.

The FEA thermal analyses are applied to find out residual stress component contours in the weld bead (see Fig. 19a-c). The stress distributions are at top surface of the weldment and various results are plotted along the surface. In addition, the corresponding von-Mises equivalent stress distribution are plotted in order to determine the final residual stresses, as shown in Fig. 19d.

Residual stresses developed along the $x$ direction are shown in Fig. 20a. The highest tensile stresses are observed at the weld zone portion as compared to other portions in the weldment. For normal stresses along the thickness $y$ shown in Fig. 20b, the stress distribution at the support of the thicknesses has a higher compressive stress value as compared to the other locations. For the stresses along the $z$ direction shown in Fig. 20c, the highest peak values of compressive stresses are located at the top surface of the weld bead of the weldment. The von-Mises equivalent stress values are higher at weld bead and there is a small reduction in the maximum value of the stress at the bottom of the weld bead with respect to those values at the top surface of the weld bead, as shown in Fig. 20d.

\section{Conclusions}

The following conclusions are drawn from the present research work carried out on AISI321 grade steel of $10 \mathrm{~mm}$ thickness using GMAW process.

(i) Mathematical models are developed for $H_{\mathrm{B}}, W_{\mathrm{B}}$ and $P_{\mathrm{B}}$. The statistical significance of the fitted models and variables involved as the response parameters are tested 


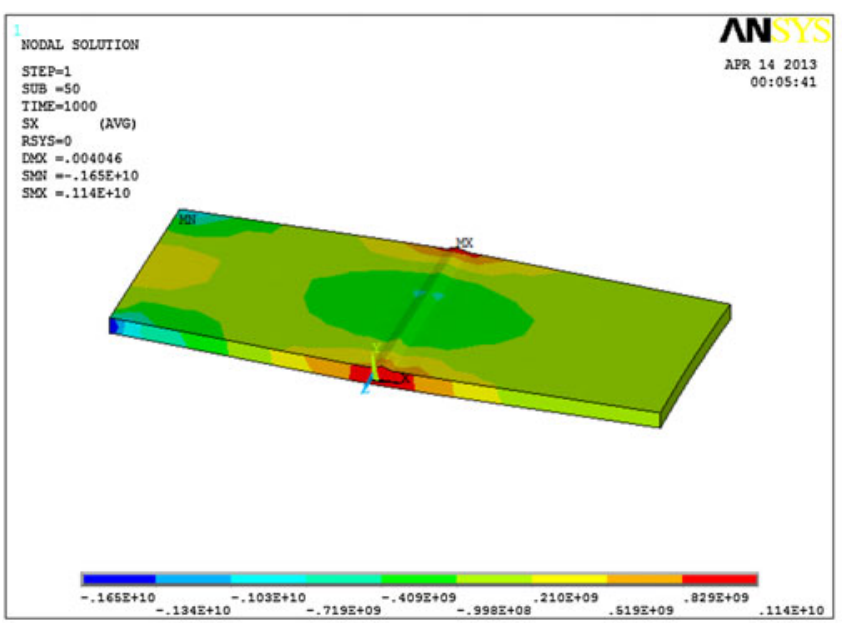

(a)

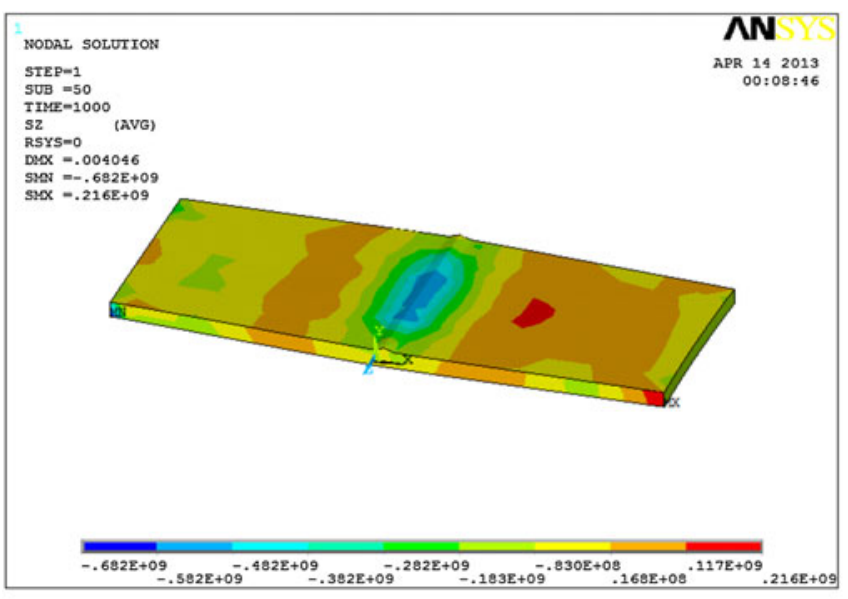

(c)

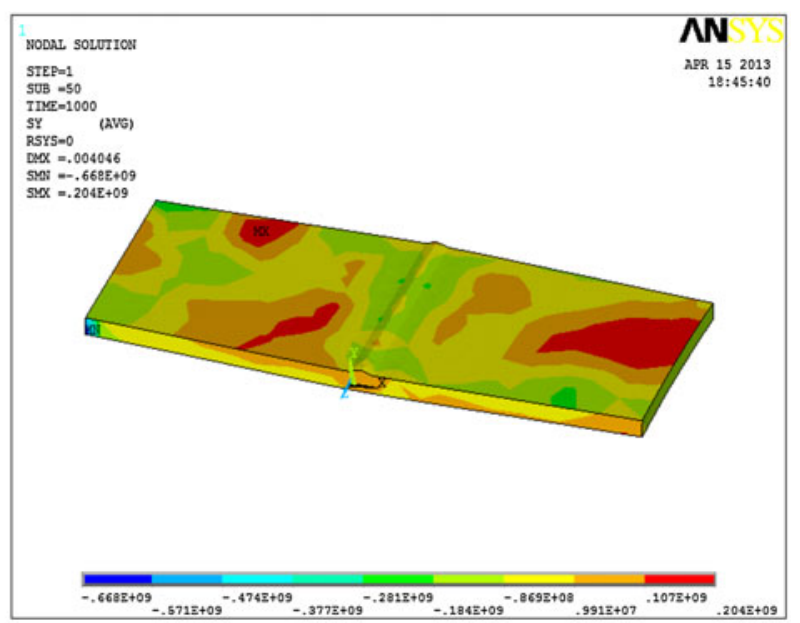

(b)

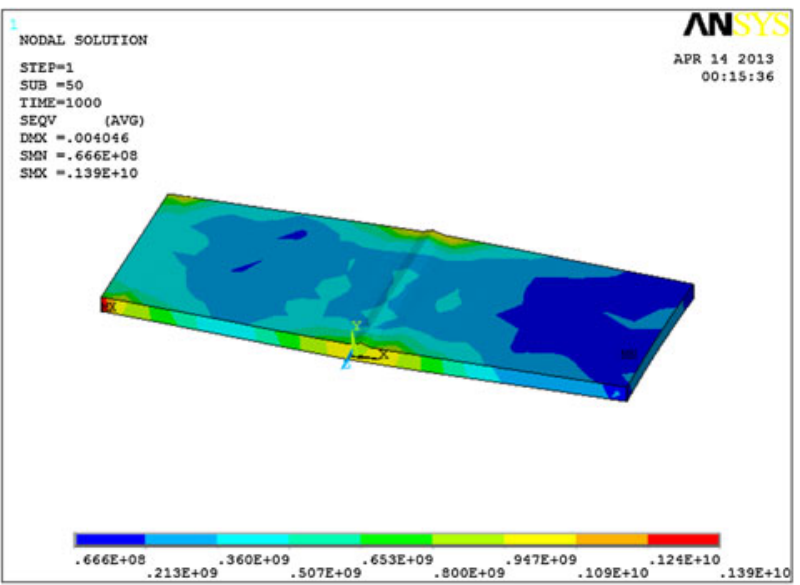

(d)

Fig. 19 Residual stress component of weldment: a Transverse stress along SX, b Transverse stress along SY, c Transverse stress along SZ, d von-Mises stresses

by ANOVA. In addition, the lack-of-fit test is used and $F$-ratios are compared with the tabulated values. These show that the developed models are reasonably accurate. The effects of process parameters on bead geometry parameters and mechanical properties like hardness of the weldment show that proper selection of all the four input parameters gives good weld bead geometry.

(ii) Microstructures at three different zones viz: i) at the base metal; ii) at the HAZ and iii) at the weld zone. The transverse sections of the weldment show no weld defects and the weld joint shows acceptable fusion. Metal flow in the weld zone and away from the weld zone is acceptable. Microstructure at the base metal shows uniform grain size distribution. Polygonal and equiaxed white grains of ferrite occupy about $99.5 \%$ volume and the rest dark phases are resolved pearlite.
Annealing twins and deformation bands parallel to the rolling direction are also observed. The coarse grain structure on one side and cast structure on the other side with transient effect are observed in HAZ region. The weld zone shows a typical cast structure and the directionally solidified columnar dendrites.

(iii) The FEAs are applied to find residual stresses and corresponding von-Mises stresses. Transient thermal analysis gives time evolutions of the temperature and residual stress distribution due to conduction and convection with time variation. It is observed that high temperature exits in the welded zone and temperature is distributed along the length of the weldment in conduction. The convection takes place in the middle part of the weldment. 


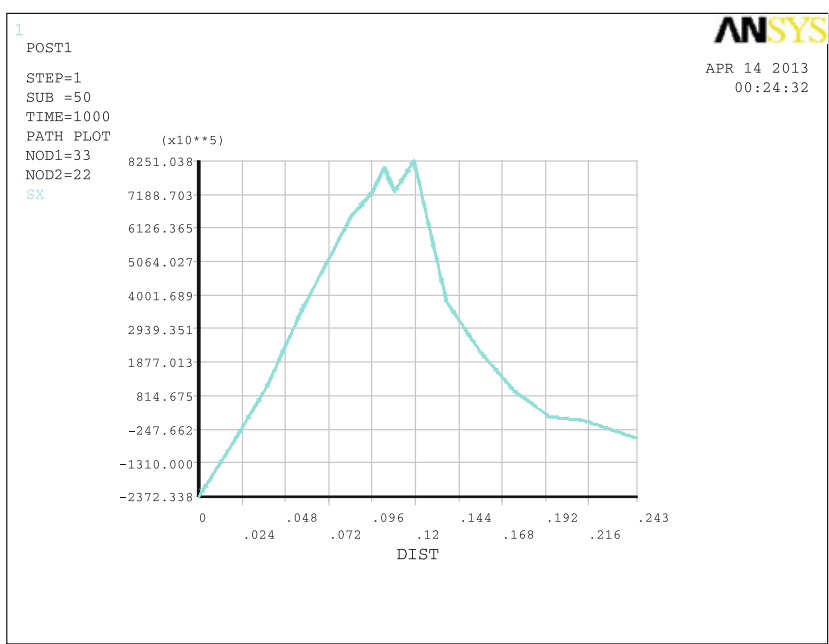

(a)

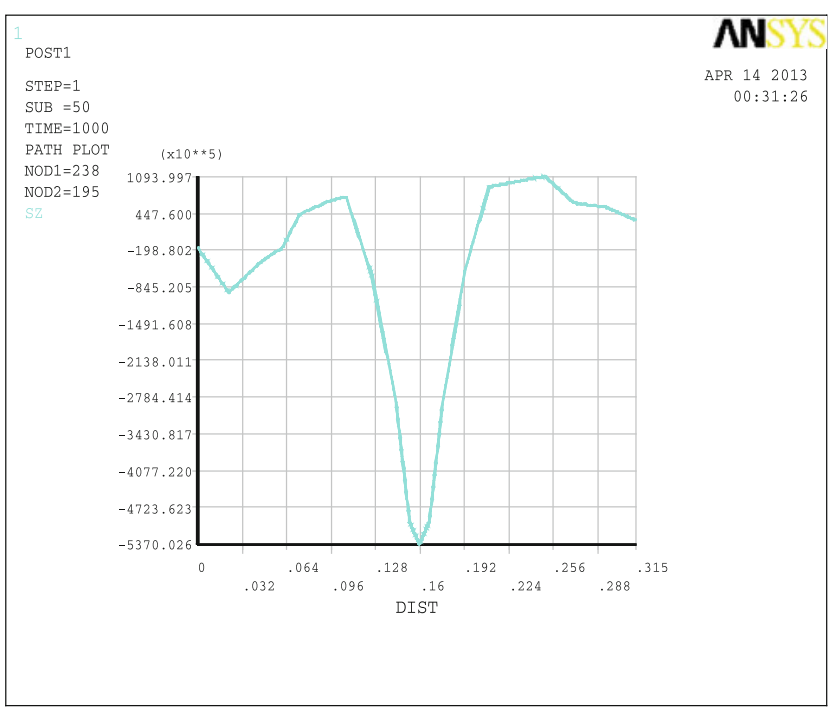

(c)

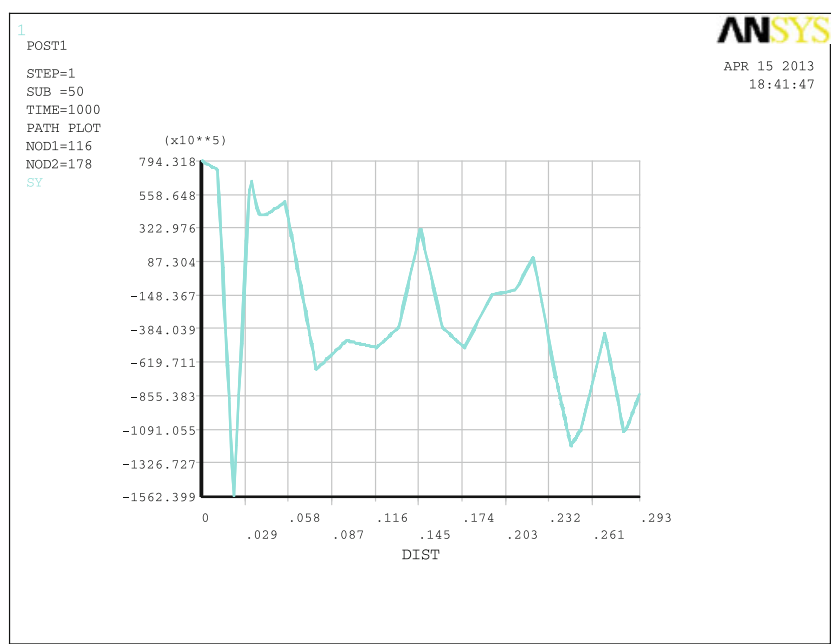

(b)

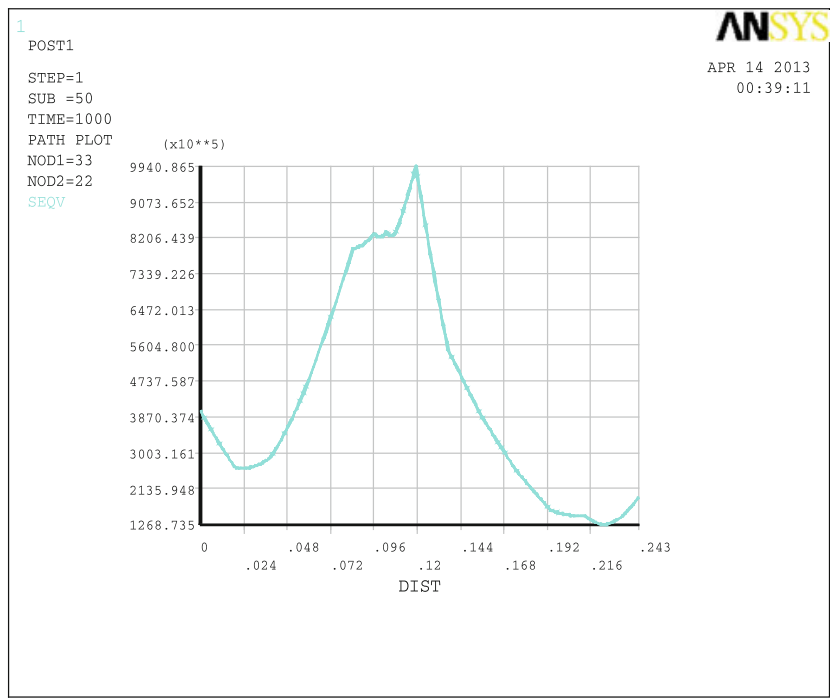

(d)

Fig. 20 Stress distribution transverse to weld bead at top surface. a Transverse stress along SX vs distance, b Transverse stress along SY vs distance, $\mathbf{c}$ Transverse stress along SZ vs distance, $\mathbf{d}$ von-Mises stresses vs distance

\section{References}

1. Quintino L, Allum CJ (1981) Pulsed GMAW: interactions between process parameters-part 1. Weld Mater Fabr 85:5-9

2. Smati Z (1985) Automated pulsed MIG welding. Metal Constr $18: 38-44$

3. Ganjigatti JP, Pratihar DK, Choudhary AR (2006) Modeling of the MIG welding process using statistical approaches. Int J Adv Manuf Technol 30:669-676

4. Tham G, Yaakub MY, Abas SK et al (2012) Predicting the GMAW 3F T-Fillet geometry and its welding parameter. Int Symp Robotics Intel Sens Procedia Eng 41:1794-1799

5. Xu W, Wu C, Zou D (2008) Predicting of bead undercut defects in high speed gas metal arc welding. Frontier Mater Sci 2:402-408

6. Katherasan D, Elias JV, Sathiya P et al (2012) Simulation and parameter optimization of flux cored arc welding using artificial neural network and particle swarm optimization algorithm. J Intell Manuf 12:675-684
7. Rao PS, Gupta OP, Murty SSN et al (2009) Effects of process parameters and mathematical model for the prediction of bead geometry in pulsed GMA welding. Int $\mathbf{J}$ Adv Manuf Technol 45:496-505

8. Campbell SW, Galloway AM, McPherson NA (2012) Artificial neural network prediction of weld geometry performed using GMAW with alternating shielding gases. Weld J $91: 174 \mathrm{~s}-181 \mathrm{~s}$

9. Ganjigatti JP, Pratihar DK, Choudhury AR (2007) Global versus cluster-wise regression analyses for prediction of bead geometry in MIG welding process. J Mater Process Technol 189:352-366

10. Shiang SJ, Fong TY, Bin YJ (2011) Principal component analysis for multiple quality characteristics optimization of metal inert gas welding aluminum foam plate. Mater Des 32:1253-1261

11. Pal S, Pal SK, Samantaray AK (2008) Artificial neural network modeling of weld joint strength prediction of a pulsed metal inert gas welding process using arc signals. J Mater Process Technol 202:464-474 
12. Malviya R, Pratihar DK (2011) Tuning of neural networks using particle swarm optimization to model MIG welding process. Swarm Evolut Comput 1:223-235

13. Benyounis KY, Olabi AG (2008) Optimization of different welding process using statistical and numerical approaches: a reference guide. Adv Eng Softw 39:483-496

14. Palani PK, Murugan N (2007) Optimization of weld bead geometry for stainless steel claddings deposited by FCAW. J Mater Process Technol 190:291-299

15. Murugan N, Parmar RS (1994) Effects of MIG process parameters on the geometry of the bead in the automatic surfacing of stainless steel. J Mater Process Technol 41:381-398

16. Cochran WG, Cox GM (1957) Experimental designs. Wiley, New York

17. Sudhakaran R, Murugan V, Sethilkumar KM et al (2011) Effects of welding process parameters on weld bead geometry and optimization of process parameters to maximize depth to width ratio for stainless steel gas tungsten arc welded plates using genetic algorithm. J Sci Res 62:76-94

18. Systat (1991) SYSTAT version 12. Systat Inc, San Jose

19. Hamza RMA, Aloraier A, Al-Faraj EA (2011) Investigation of the effect of welding polarity on joint bead geometry and mechanical properties of shielded metal arc welding process. J Eng Technol 2:100-111

20. Kolhe KP, Datta CK (2008) Prediction of microstructure and mechanical properties of multipass SAW. J Mater Process Technol 197:241-249

21. Capriccioli A, Frosi P (2009) Multipurpose ANSYS FE procedure for welding processes simulation. Fus Eng Des 84:546-553

22. Kong F, Ma J, Kovacevic R (2011) Numerical and experimental study of thermally induced residual stress in the hybrid laser-GMA welding process. J Mater Process Technol 211:1102-1111 